\title{
Investigating the Structure-Activity Relationship of Marine Polycyclic Batzelladine Alkaloids as Promising Inhibitors for SARS-CoV-2 Main Protease $\left(\mathrm{M}^{\mathrm{pro}}\right)$
}

Alaa M. Elgohary, ${ }^{1}$ Abdo A. Elfiky, ${ }^{1 *}$ Florbela Pereira ${ }^{2}$, Tarek Mohamed Abd El-Aziz ${ }^{3,4}$ Mansour Sobeh ${ }^{5}$ Reem K. Arafa ${ }^{6,7}$ and Amr El-Demerdash ${ }^{8,9 *}$

${ }^{1}$ Department of Biophysics, Faculty of Sciences, Cairo University, Giza 12613, Egypt

${ }^{2}$ LAQV-REQUIMTE, Department of Chemistry, NOVA School of Science and Technology, Universidade Nova de Lisboa, 2829-516 Caparica, Portugal

${ }^{3}$ Department of Zoology, Faculty of Sciences, Minia University, El-Minia 61519, Egypt

${ }^{4}$ Department of Cellular and Integrative Physiology, University of Texas Health Science Centre at San Antonio, San Antonio, TX 78229, USA

${ }^{5}$ AgroBioSciences Department, Mohammed VI Polytechnic University (UM6P), Ben Guerir, Morocco

${ }^{6}$ Drug Design and Discovery Laboratory, Helmy Institute for Medical Sciences, Zewail City of Science and Technology, Giza 12578, Egypt

${ }^{7}$ Biomedical Sciences Program, University of Science and Technology, Zewail City of Science and Technology, Giza 12578, Egypt

${ }^{8}$ Division of Organic Chemistry, Department of Chemistry, Faculty of Sciences, Mansoura University, Mansoura 35516, Egypt

${ }^{9}$ Department of Biochemistry and Metabolism, the John Innes Centre, Norwich Research Park, Norwich NR4 7UH, UK

*Correspondences: dr_abdo@cu.edu.eg, abdo@sci.cu.edu.eg (Abdo A. Elfiky); Amr.ElDemerdash@jic.ac.uk, a_eldemerdash83@mans.edu.eg (Amr El-Demerdash)

Tel: +20 1003260523 (Abdo A. Elfiky); +447834240424 (Amr El-Demerdash) 


\section{Highlights:}

- COVID-19 is unprecedented health crisis that exploded globally late 2019.

- Marine natural products (MNPs) are powerful chemical tools that might be able to compete COVID-19 outbreak.

- Extensive computational screening supported with structure-activity relationships (SARs) studies recommended the marine batzelladine alkaloids, particularly batzelladines H-I (8-9) as promising antiviral hits for hunting SARS-CoV-2 main protease.

\section{Keywords:}

SARS-CoV-2; virtual screening; molecular docking; molecular dynamics simulation; marine sponges, batzelladines, guanidine alkaloids, structure-activity relationships (SARs).

\section{Abbreviations:}

ADME: Absorption, distribution, metabolism, and excretion

COVID-19: Coronavirus disease 2019

SARS-CoV-2: severe acute respiratory syndrome-coronavirus 2

MBAs: Marine Batzelladine Alkaloids

MNPs: Marine Natural Products

$\mathbf{M}^{\text {Pro: }}$ Main Protease

MDock: Molecular Docking

MD: Molecular Dynamic Simulations

SARs: Structure-Activity Relationships

VMD: Visual Molecular Dynamics

RMSD: Root Mean Square Deviation

MM-GBSA: Molecular Mechanics-Generalized Born Oppenheimer Surface Area

UFF: Universal Force Field

SASA: Solvent Accessible Surface Area 


\section{Abstract}

Over a span of two years ago, since the emergence of the first case of the novel coronavirus (SARS-CoV-2) in China, the pandemic has crossed borders causing serious health emergencies, immense economic crisis and impacting the daily life worldwide. Despite the discovery of numerous forms of precautionary vaccines along with other recently approved orally available drugs, yet effective antiviral therapeutics are necessarily needed to hunt this virus and its variants. Historically, naturally occurring chemicals have always been considered the primary source of beneficial medications. Considering the SARS-CoV-2 main protease $\left(\mathrm{M}^{\text {pro }}\right)$ as the duplicate key element of the viral cycle and its main target, in this paper, an extensive virtual screening for a focused chemical library of 15 batzelladine marine alkaloids, was virtually examined against SARS-CoV-2 main protease $\left(\mathrm{M}^{\text {pro }}\right)$ using an integrated set of modern computational tools including molecular docking (MDock), molecule dynamic (MD) simulations and structure-activity relationships (SARs) as well. The molecular docking predictions had disclosed four promising compounds including batzelladines H-I (8-9) and batzelladines F-G (6-7), respectively according to their prominent ligand-protein energy scores and relevant binding affinities with the $\left(\mathrm{M}^{\mathrm{pro}}\right)$ pocket residues. The best two chemical hits, batzelladines H-I (8-9) were further investigated thermodynamically though studying their MD simulations at $100 \mathrm{~ns}$, where they showed excellent stability within the accommodated $\left(\mathrm{M}^{\mathrm{pro}}\right)$ pocket. Moreover, SARs studies imply the crucial roles of the fused tricyclic guanidinic moieties, its degree of unsaturation, position of the $\mathrm{N}-\mathrm{OH}$ functionality and the length of the side chain as a spacer linking between two active sites, which disclosed fundamental structural and pharmacophoric features for efficient proteinligand interaction. Such interesting findings are greatly highlighting further in vitro/vivo examinations regarding those marine natural products (MNPs) and their synthetic equivalents as promising antivirals. 


\section{Graphical abstract}
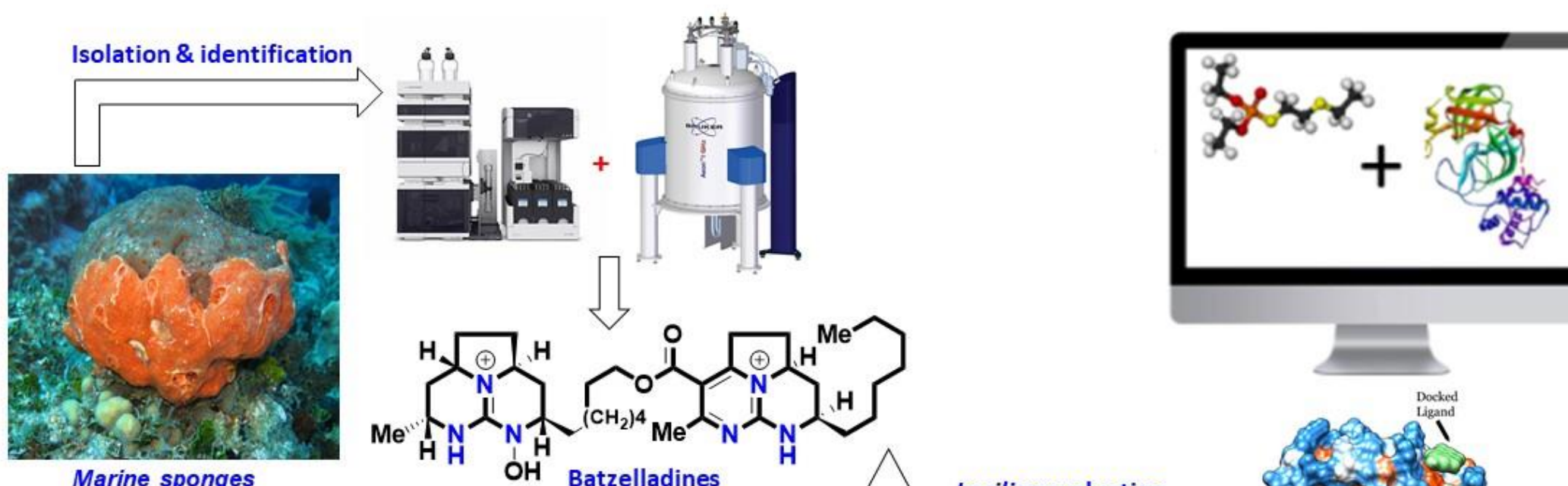

Marine sponges

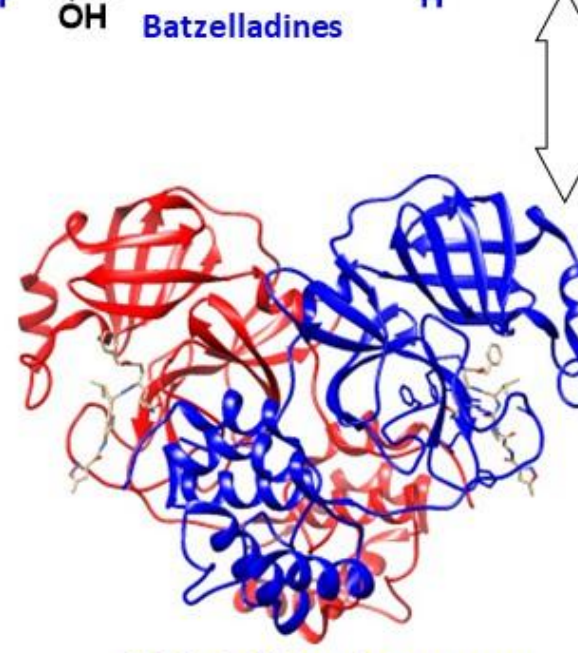

In silico evaluation
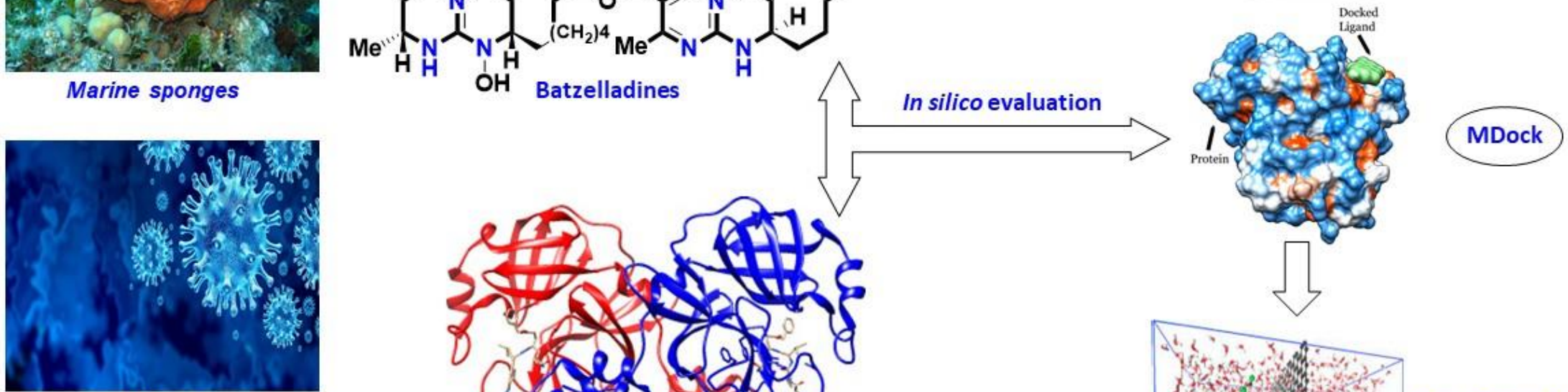

COVID-19

Target protein selection

SARS-CoV-2 main protease

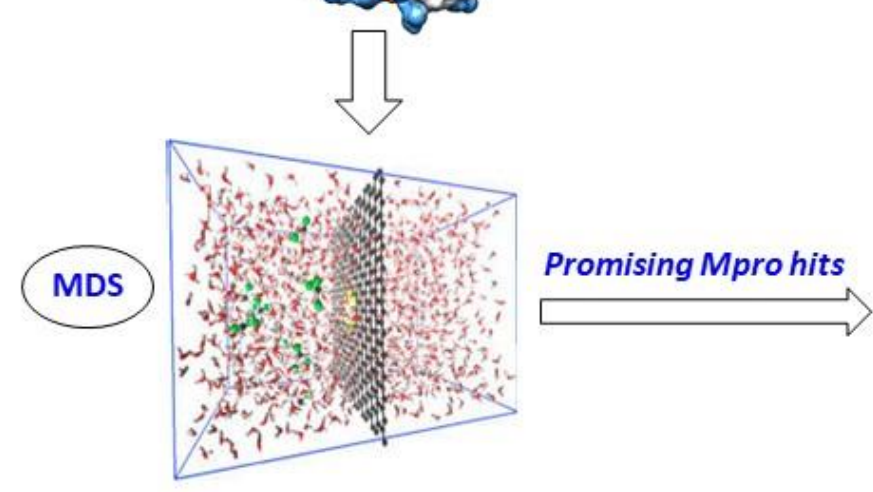




\section{Introduction}

Over the span of seven decades, marine natural products (MNPs) and their synthetic congeners have been revitalised as a vigorous respiratory and robust platform for global pharmaceutical industry and drug led discovery programmes [1]. Indeed, in 1950, Bergmann and his co-workers reported the first two marine compounds spongothymidine and spongouridine from the Caribbean marine sponge Cryptotethya crypta [2-4]. Twenty years later, they have been synthetically optimized to furnish the first two clinically approved marine drugs, commercially known as cytarabine (Cytosar-Uß, Depocyst ${ }^{\circledR}$, approved by FDA in 1969 for cancer treatment) and vidarabine (Vira-A®, approved by FDA in 1976 as antiviral) [5-8].

Up to 2022, successful seventeen marine-derived drugs have been clinically approved for markets for the treatment of numerous medical and life induced challenges, in addition to twenty other candidates, which are currently being investigated in different preclinical trials [9-12]. Likely, such unique habitat presents thousands of new and novel compounds that are being disclosed each year from different marine organisms like sponges, soft corals, tunicates, algae, and microbes [13-17].

Along the discovery side, numerous chemical synthetic efforts are being expressed for the led optimization purposes towards a panel of structurally diverse marine compounds for various biomedical applications particularly as antiviral, anticancer, and against other nighligated diseases. Bearing such successful stories that imply the vast capacity of marine-derived natural products as a versatile hotspot for mining promising drugs leads that feature unprecedented structural and biological diversifications [18-20].

Recently in 2021-2022, several research reports highlighted plitidepsin, a small cyclic peptide previously isolated from the tunicate Aplidium albicans and originally approved as anticancer to disclose very promising in vitro antiviral activity against SARS-CoV-2 with $\mathrm{IC}_{90}=0.88 \mathrm{nM}$ and might be a strong drug candidate that gives a hope for future treating of COVID-19 [21-24].

Batzelladines is one fascinating class of a broad family of polycyclic guanidine-derived alkaloids which exclusively are restricted to the marine origin [25]. Chemically, they feature two main fused guanidinic portions linking together via an ester functionality, where a principle tricyclic system named clathriadic acid is assembled to another clathriadic acid or a crambescin bicyclic moiety [26]. Biogenetically, those marine alkaloids are supposed to be generated via sequential modes of cyclization between a polyketide-derived chain and a putative guanidine precursor along with different oxidation degrees to afford such complex metabolites [25, 27-29]. 
Batzelladines derived alkaloids are known to display a vast array of biological activities like cytotoxicity, antimicrobial, anti-leishmanial and anti-parasitic [25]. Interestingly, a notable number of naturally occurring batzelladines and their synthetic analogues displayed powerful antiviral activities such as anti-HIV-1, Anti-AIDS, anti-HSV-1 [3037].

Considering the central role of SARS-CoV-2 $\left(\mathrm{M}^{\mathrm{pro}}\right)$, along with the powerful antiviral activities of the MNPs under investigation and as a part of our continuous program to identify pharmacologically active MNPs [38-40] with adequate antiviral potentiality against SARS-CoV-2 (COVID-19 pandemic) [41-43], herein we comprehensively exploring virtually the SARs of a focused library of fifteen marine batzelladine alkaloids against the dimeric form of SARS-CoV-2 $\left(\mathrm{M}^{\text {pro }}\right)$ using an integrated package of advanced computational tools including (MDock), (MD) simulations and (SARs).

\section{Material and Methods}

\subsection{Preparation of the Screening Library and Protein Structure}

Using Avogadro 1.2 software, ligand structures were drawn and optimized by the universal force field (UFF) [44, 45]. Further optimization was performed utilizing the parameterization method 6 (PM6) of SCIGRESS 3.0 software followed by infra-red calculations at the same level of the semi-empirical method [46]. The positive control ligands $\mathrm{O} 6 \mathrm{~K}$ and $\mathrm{N} 3$ were also optimized using the same protocol after retrieval from the PDB structures 6Y2G and 6LU7, respectively [47, 48]. Finally, all the ligands were prepared for docking by AutoDock tools 1.5.6 software [49]. Charges (Kollman and Gasteiger) were added while the PDBQT files of the ligands were saved for the docking calculations. Meanwhile, the $\mathrm{M}^{\text {pro }}$ structure (PDB ID: 6Y2G) was separately prepared for the MD simulations and the MDock studies.

\subsection{Molecular Docking (MDock)}

After clustering, five representative conformations, representing the different clusters, were prepared for the docking study using AutoDock Tools software. AutoDock Vina 1.2.2 was used to dock the ligands to the protein active site defined by H41 and C145 [50]. During the docking calculations for all ligands, a flexible ligand in a flexible active site was maintained. The search box was set to cover the dyad H41 and C145 with size $30 \times 30 \times 30 \AA^{3}$ centered at $(25.2,46.0,40.6) \AA$. 


\subsection{Molecular Dynamics (MD) Simulations}

MD simulation of the $\mathrm{M}^{\text {pro }}$ structure was performed by the NAMD 2.13 software utilizing CHARMM 36 force field $[51,52]$. The calculations were performed for $100 \mathrm{~ns}$ over the SHAHEEN HPC platform in the King Abdullah University for Science and Technology (KAUST), Saudi Arabia (project no. 1482). The simulation was performed in the TIP3P water model at $1 \mathrm{~atm}$, and $310 \mathrm{~K}$ with $\mathrm{NaCl}$ added for the protein-water solution to be of a total concentration of $154 \mathrm{mM}[53,54]$. Periodic boundary condition was utilized with a cubic simulation box. After the simulation, the trajectories were clustered using UCSF Chimera software 1.14 and analyzed, as will be shown in the results section using VMD 1.9.3 software and in-house codes $[55,56]$. After the binding energy calculations, we ranked the ligands according to their binding energies to $\left(\mathrm{M}^{\text {pro }}\right)$. The best two ligand- $\mathrm{M}^{\text {pro }}$ complexes $\left(\mathbf{8}-\mathrm{M}^{\text {pro }}\right.$ and $\left.\mathbf{9}-\mathrm{M}^{\mathrm{pro}}\right)$ and the $\mathrm{O} 6 \mathrm{~K}-\mathrm{M}^{\text {pro }}$ complex were subjected to another 100 ns MD simulations run with the same protocol. After the run, the Molecular MechanicsGeneralized Born Oppenheimer Surface Area (MM-GBSA) was calculated using Amber tools to deconvolute the binding affinity as a per-residue contribution [57].

\subsection{In-silico Prediction of Physicochemical properties, Pharmacokinetic and Toxicity profiles}

The pharmacokinetic properties of the fifteen compounds in our screening library were calculated using the SWISS-ADME platform (https://www.swissadme.ch, accessed on 04 February 2022). The physicochemical properties predicted here were lipophilicity, reported as Log Po/w (WLOGP); water solubility class; and blood-brain barrier (BBB) penetration, in addition to pan-assay interference alerts (PAINS) [58, 59].

The potential toxicity profiles of these compounds were predicted using the pkCSM online webtool (http://biosig.unimelb.edu.au/pkcsm/prediction, accessed on 04 February 2021) to predict the safety of these small molecules upon ingestion in human and animal models, with respect to toxicological effects on hERG-I inhibition [60].

\subsection{Identification of Polycyclic Marine Batzelladine Alkaloids (MBAs)}

A focused library of fifteen batzelladines guanidine alkaloids (1-15) were previously reported from several marine sponges, belonging to the genera Batzella, Clathria and Monanchora (Schemes 1-2). For comprehensive detailed isolations and structural characterizations, see El-Demerdash et al. [25, 61]. 

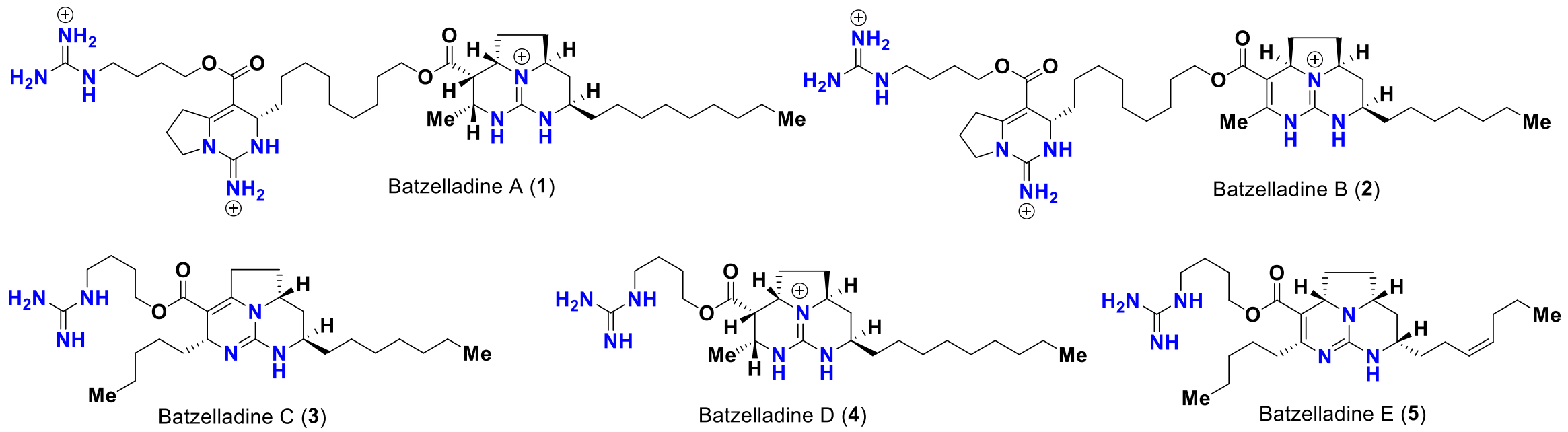

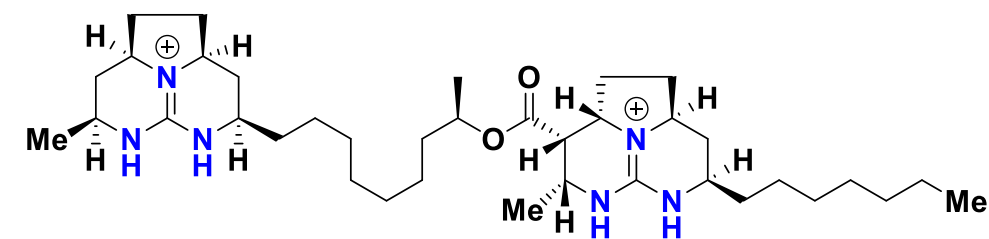

Batzelladine F (6)

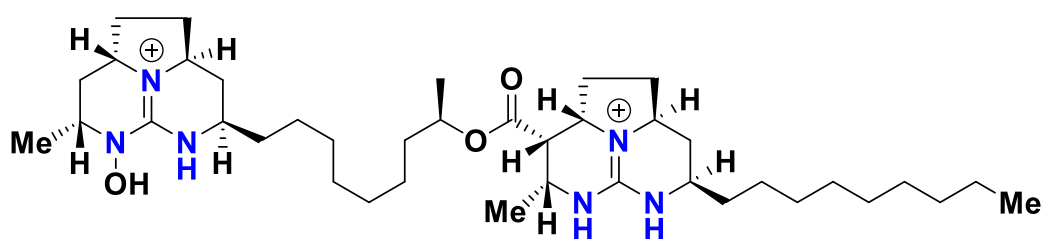

Batzelladine $\mathrm{G}(\mathbf{7})$

Scheme 1. Reported antiviral batzelladines (1-7) 

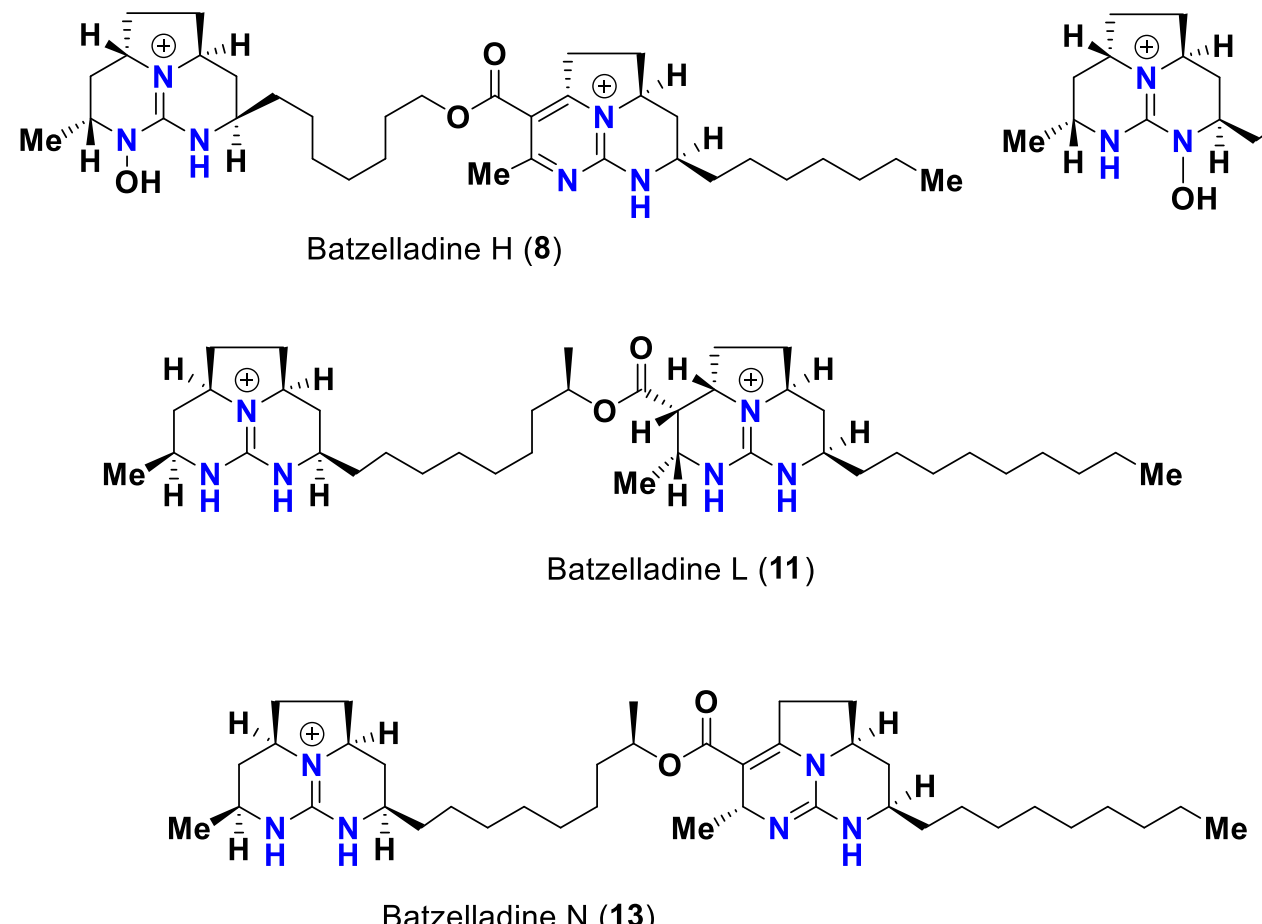

Batzelladine N (13)
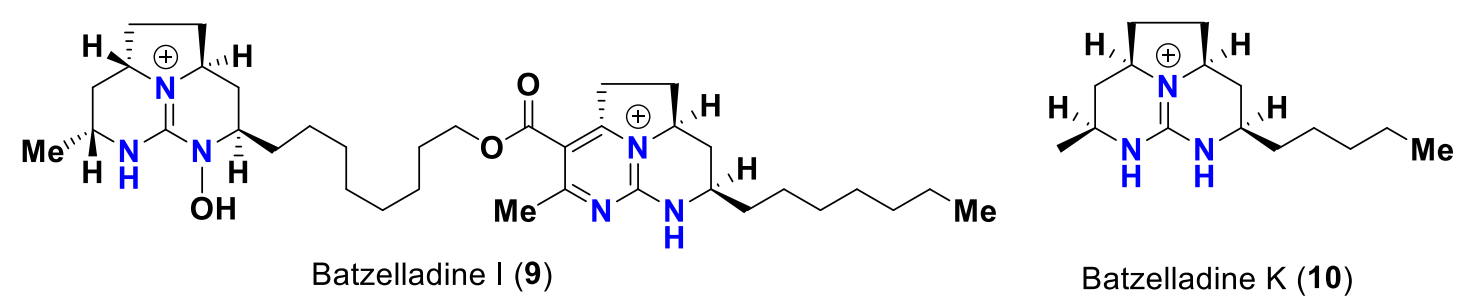

Batzelladine M (12)

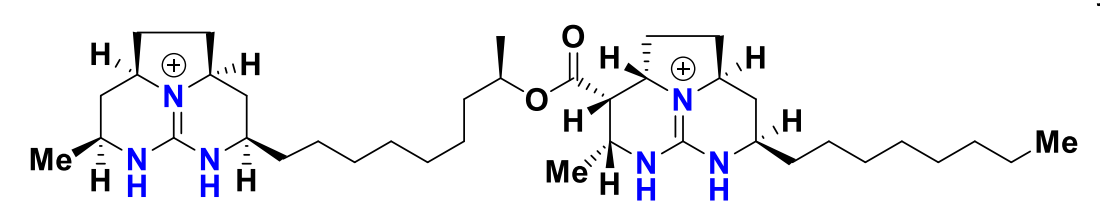

Norbatzelladine L (15)

Scheme 2. Reported antiviral batzelladines (8-15) 


\section{Results and Discussions}

\subsection{Molecular Docking (MDock) and Binding Energies Studies}

In this study, we studied fifteen marine polycyclic batzelladine alkaloids against SARSCoV-2 $\mathrm{M}^{\text {pro }}$ in silico, aiming to evaluate their binding energies and binding mode to the active site of $\mathrm{M}^{\text {pro }}$. Before discussing the compounds' binding energies, we represent the analysis curves for the MD simulations of the $\mathrm{M}^{\text {pro }}$ of the SARS-CoV-2 system (a dimer) using VMD software and some in-house analysis codes. Figure 1A shows the Root Mean Square Deviation (RMSD) in $\AA$ (blue line), the Radius of Gyration (RoG) in $\AA$ (orange line), and the Surface Accessible Surface Area (SASA) in $\AA^{2}$ (gray line). As reflected from the curves, the system was equilibrated during the first $10 \mathrm{~ns}$ of the simulation with an RMSD value of $1.8 \AA$. Additionally, the RoG and SASA values (26.0 $\AA$ and 27100 $\AA^{2}$, respectively) and patterns indicate system equilibration during the simulation period. Simultaneously, the total number of H-bonds present in the protein was found to be stable during the simulation period, as shown in figure $1 \mathrm{~B}$, with an average number of the total H-bonds of 924 (in the protein dimer). The per-residue Root Mean Square Fluctuations (RMSF) in $\AA$ is demonstrated in figure $1 \mathrm{C}$, where the two chains of the $\mathrm{M}^{\text {pro }}$ are shown in different colors. The active site dyads H41 and C145 are indicated in the RMSF curves at minimum fluctuations (RMSF $<1 \AA$ ). During the simulation, there are no identified high fluctuations regions (all RMSF $<2.26 \AA$ ).

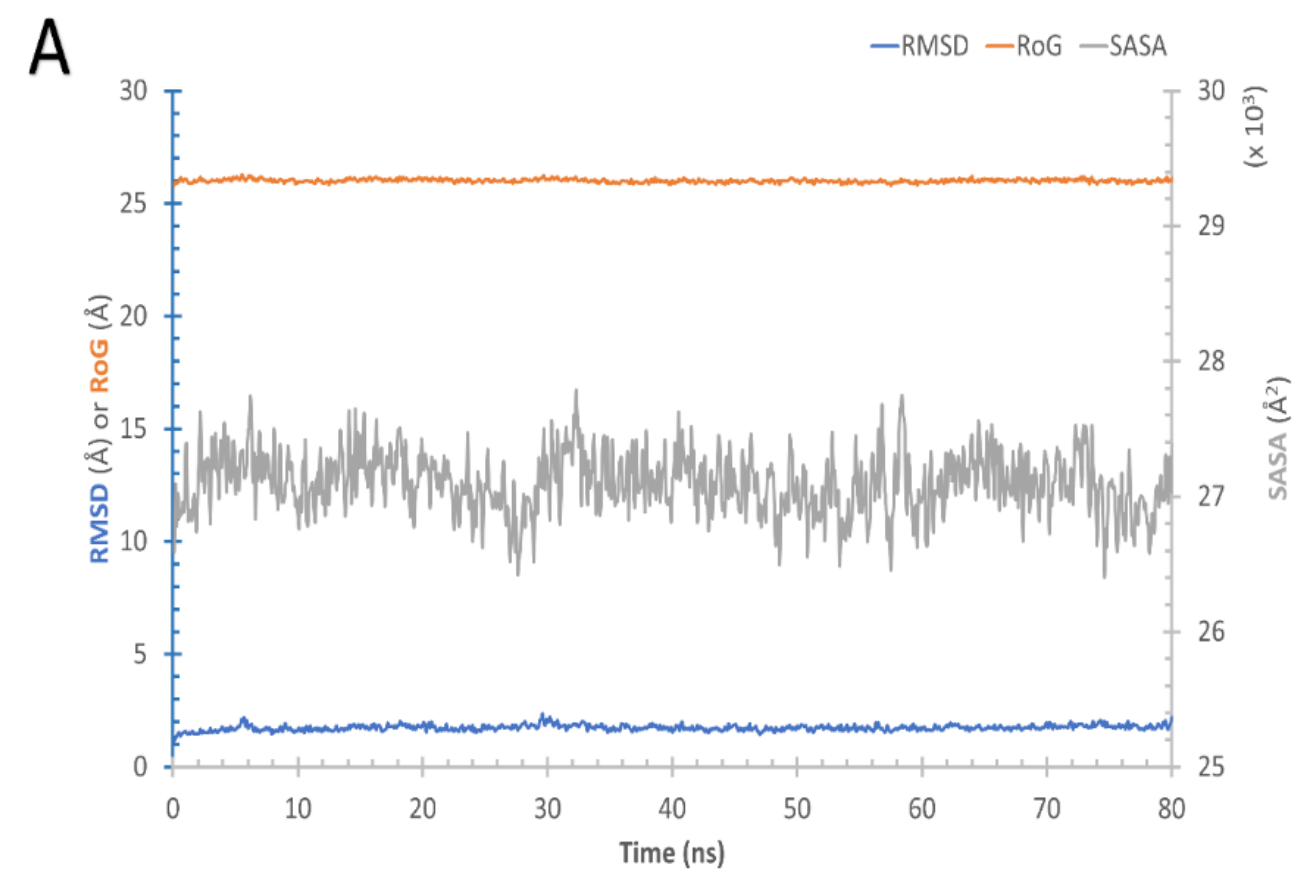



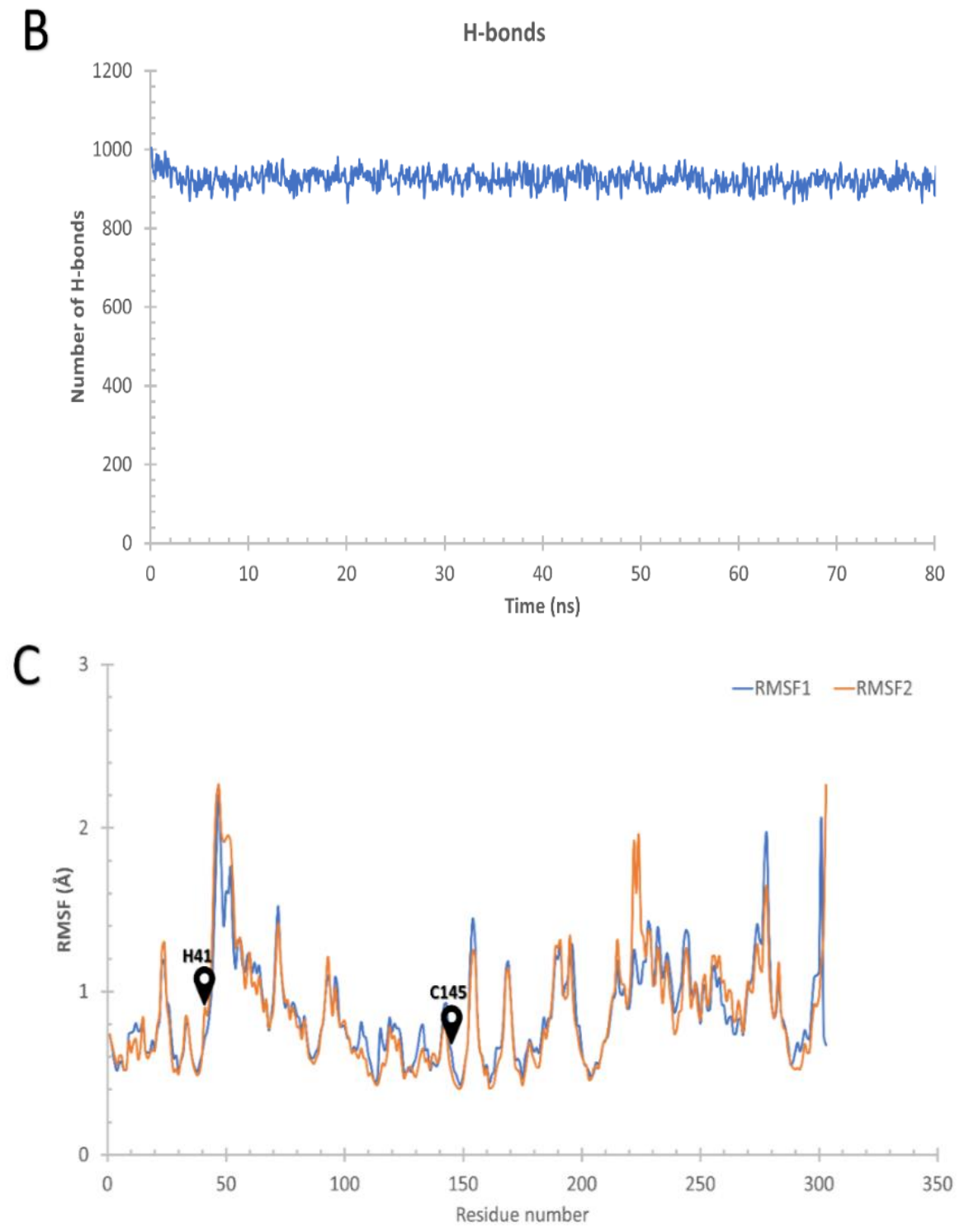

Figure 1: A The Root-mean-square deviation (RMSD) (blue) in $\AA$, Radius of Gyration (RoG) (orange) in $\AA$, and Surface Accessible Surface Area (SASA) (gray) in $\AA^{2}$, versus the simulation time in ns. B The total number of the H-bonds versus the simulation time. C: The per-residue Root-mean-square fluctuations (RMSF) in $\AA$ for the two chains of the dimeric $\mathrm{M}^{\text {pro }}$.

A redocking experiment is essential in testing the docking protocol quality, as such the co-crystallized ligand $\mathbf{O 6 K}$ was retrieved from the crystal structure of $\mathrm{M}^{\text {pro }}$ (PDB ID: $6 \mathrm{Y} 2 \mathrm{G}$ ) and docked to the protein dimer. PyMOL software was utilized to superpose the docked complex to the solved structure. The root-mean-square displacement (RMSD) between the complex and the solved structure was $0.899 \AA$, where the number of fitted atoms was 1437, indicating high structural similarities. Figure 2A shows the average binding affinities calculated utilizing five different conformations of the $\mathrm{M}^{\text {pro }}$ after the $100 \mathrm{~ns}$ MD simulation. The error bars represent the standard deviation. The positive controls (O6K and N3) are shown in red columns, while the best two compounds 
(batzelladines H-I, 8-9) are in green. Additionally, Figure 2B displays the hydrophobic contacts (dashed-gray lines), which represent the interactions established between the ligands (orange sticks) and the $\mathrm{M}^{\mathrm{pro}}$ residues (blue sticks). As reflected from figure $2 \mathrm{~A}$, the average binding energies for most of the compounds under investigation are in good agreement with the positive controls, with compound $\mathbf{1 0}$ (batzelladine K) as an exception having a significantly low affinity against the $\mathrm{M}^{\text {pro }}$ active site $(-5.46 \pm 0.30 \mathrm{kcal} / \mathrm{mol})$. For the rest of the compounds, the average binding energies ranged from $-7.12 \pm 0.60(8)$ down to $-6.22 \pm 0.37(\mathbf{1 4}) \mathrm{kcal} / \mathrm{mol}$, while for the positive control, binding energies were found to be $-7.36 \pm 0.34 \mathrm{kcal} / \mathrm{mol}$ and $-6.36 \pm 0.31 \mathrm{kcal} / \mathrm{mol}$ for $\mathbf{O 6 K}$ and $\mathbf{N 3}$, respectively.
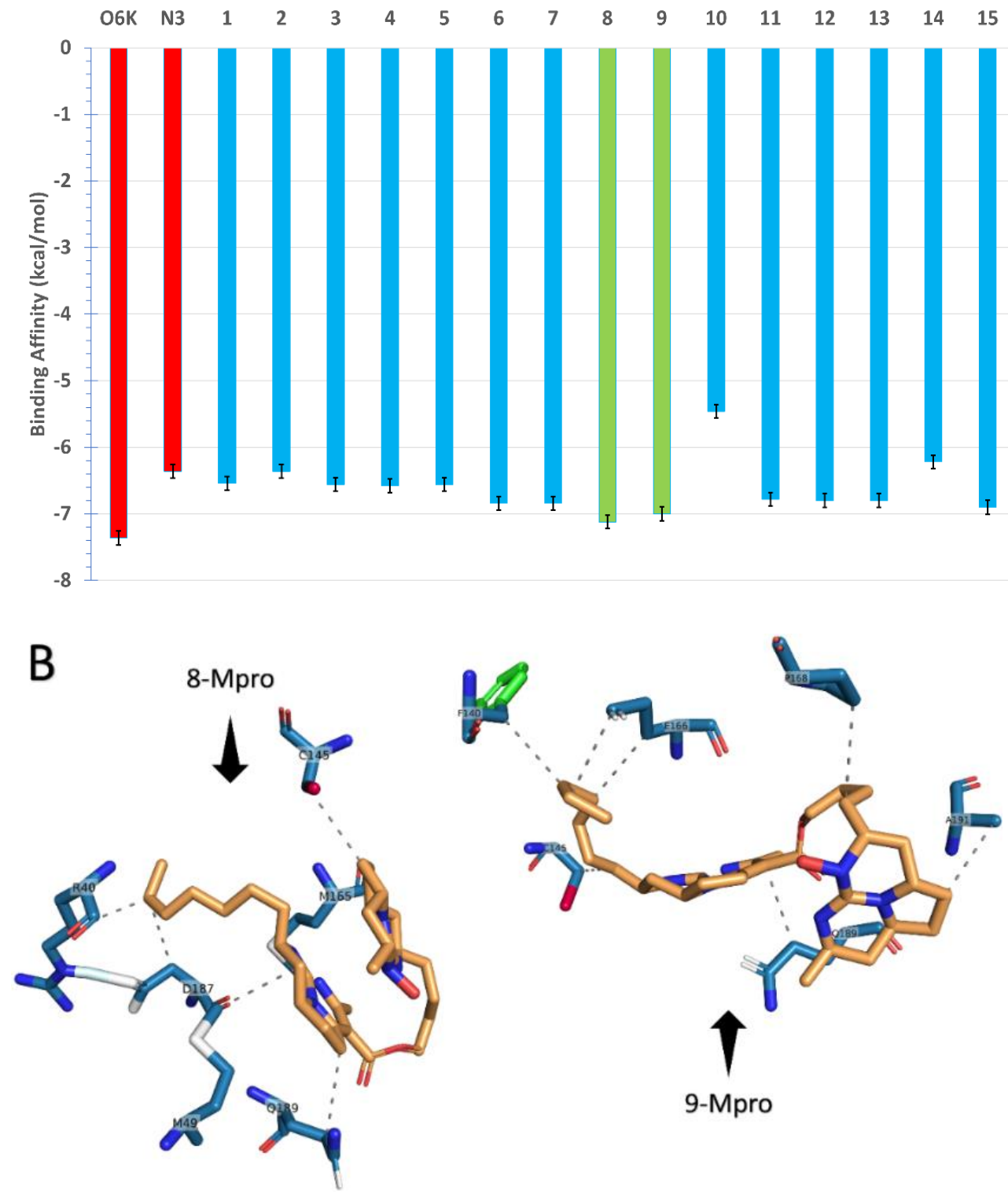

Figure 2: A The average binding energies of the tested compounds (1-15) and the positive controls O6K and N3 (red columns) retrieved from the structures (PDB IDs: 6Y2G and 6LU7, respectively). The best two compounds (8 and $\mathbf{9})$ are shown in green. B Binding mode of the best two compounds $(\mathbf{8}$ and $\mathbf{9})$ depicted by PyMOL software, where orange and green sticks represent the ligands and the protein residues, respectively. Dashed-gray lines represent the hydrophobic contacts. 
The established interactions upon docking to the best representative complexes (having near average binding energy values) are listed in Table 1. Notably, the hydrophobic contact is the most reported interaction type, with few $\mathrm{H}$-bonds formed in some complexes. For example, the $\mathbf{O 6 K}-\mathbf{M}^{\text {pro }}$ complex formed the highest number of interactions, represented by eight hydrophobic contacts and $4 \mathrm{H}$-bonds. Concurrently with figure 2, the O6K-M $\mathrm{M}^{\text {pro }}$ complex reported the lowest average binding energy value (-7.36 $\pm 0.34 \mathrm{kcal} / \mathrm{mol}$ ). On the other hand, the 10 - $\mathrm{M}^{\text {pro }}$ complex showed the highest (worst) average binding energy value $(-5.46 \pm 0.30 \mathrm{kcal} / \mathrm{mol})$ and has only four hydrophobic contacts. The two complexes $\mathbf{8}-\mathrm{M}^{\text {pro }}$ and $\mathbf{9}-\mathrm{M}^{\text {pro }}$ are amongst the compounds of the highest number of formed interactions, showing 6 and 7 hydrophobic contacts, corresponding to their average binding energy values $(-7.12 \pm 0.60$ and $-7.0 \pm 0.28 \mathrm{kcal} / \mathrm{mol}$, respectively).

The residues in the $\mathrm{M}^{\text {pro }}$ that most frequently take part in interactions with the ligands are E166 (12 hydrophobic contacts and 6 H-bonds), M165 (13 hydrophobic contacts), and Q189 (12 hydrophobic contacts and one H-bond). Moreover, some other residues have moderate potential to interact with the ligands, including the active site residue, C145 (8 hydrophobic contacts and one H-bond), N142 (5 hydrophobic contacts and 3 H-bond), M49 (7 hydrophobic contacts), P168 (6 hydrophobic contacts), F140 (5 hydrophobic contacts), L167 (4 hydrophobic contacts and one H-bond), and Q192 (3 hydrophobic contacts and two H-bonds) (see Table 1).

Noteworthy, the interaction of S1 residue (red-colored in Table 1) in the Chain B of the $\mathrm{M}^{\text {pro }}$ dimer is involved, forming $\mathrm{H}$-bonds with $\mathbf{O 6 K}, \mathbf{1}, \mathbf{3}, \mathbf{4}$, and $\mathbf{1 4}$. This is reflected in the RMSF curve (Figure 1C), as intramolecular contacts stabilize the $N$-terminal region. This highlights the importance of the dimeric form during the studying of $\mathrm{M}^{\text {pro }}$ inhibitors.

Table 1: The detailed interactions established upon docking the O6K, N3, and marine compounds (1-15) against the SARS-CoV-2 M ${ }^{\text {pro }}$ (PDB ID: 6Y2G, Chain A) retrieved from PLIP webserver. Red residues represent the residues that interact with the second chain of $\mathrm{M}^{\text {pro }}$ (Chain $\mathrm{B}$ ).

\begin{tabular}{|c|c|c|c|c|}
\hline \multirow{2}{*}{ Ligand } & \multicolumn{3}{|c|}{ Hydrophobic Interactions } & \multirow{2}{*}{$\begin{array}{l}\text { Hydrogen Bonds } \\
\text { Residues involved }\end{array}$} \\
\hline & No. & Residues involved & No. & \\
\hline O6K & 4 & N142, M165, D187 and Q189 & 8 & $\begin{array}{c}\text { S1, H41, G143, S144, C145, } \\
\text { H164, and E166(2) }\end{array}$ \\
\hline N3 & 3 & T25, T26, and P168 & 2 & H164 and E166 \\
\hline 1 & 4 & N142, C145, P168, and Q189 & 3 & S1(2) and N142 \\
\hline 2 & 4 & M49, F140, M165, and E166 & 2 & L167 and Q189 \\
\hline 3 & 7 & L27, P39, M49(2), C145, E166, and Q189 & 5 & S1, L141(3), and N142 \\
\hline
\end{tabular}




\begin{tabular}{|c|c|c|c|c|}
\hline 4 & 2 & T25 and S46 & 3 & S1, N142, and E166 \\
\hline 5 & 5 & M49, F140, M165, E166, and P168 & 3 & E166 and Q192(2) \\
\hline 6 & 7 & C145, M165(2), E166, L167, Q189, and Q192 & & \\
\hline 7 & 7 & T25, M165, E166(2), L167, P168, and Q189 & 1 & G143 \\
\hline 8 & 6 & R40, M49, C145, M165, D187, and Q189 & & \\
\hline 9 & 7 & F140, C145, E166(2), P168, Q189, and A191 & & \\
\hline 10 & 4 & F140, M165, E166, and Q189 & & \\
\hline 11 & 5 & S46, F140, N142, and E166(2) & & \\
\hline 12 & 3 & L167, Q189, and Q192 & 1 & E166 \\
\hline 13 & 6 & T26, N142, C145, M165(2), and Q189 & 1 & $\mathrm{~T} 26$ \\
\hline 14 & 7 & M49, N142, C145, M165, E166, P168, and Q189 & 2 & $\mathbf{S 1}(2)$ \\
\hline 15 & 7 & M49, C145, M165(2), L167, Q189, and Q192 & & \\
\hline
\end{tabular}

\subsection{Molecular Dynamic (MD) Studies}

Figure 3 shows the MD simulation analysis of the $\mathbf{0 6 K}-\mathrm{M}^{\text {pro }}$ (blue), $\mathbf{8}-\mathrm{M}^{\text {pro }}$ (orange), and 9-M $\mathrm{M}^{\text {pro }}$ (gray). The three complexes are stable based on the RMSD (A), RoG (B), SASA (C), and the total number of H-bonds (D) curves versus the simulation time (ns). The RMSD curves indicate equilibration of the three systems after $30 \mathrm{~ns}$ with average RMSD values of about $2.25 \AA$. Additionally, the numbers of RoG, SASA, and H-bonds are averaged around $26 \AA, 28200 \AA^{2}$, and 940, respectively. The per-residue RMSF for the chain A and chain B (Figure 4) is plotted for the Apo (red) and O6K-M ${ }^{\text {pro }}$ (blue), 8-M (orange), and 9- $\mathrm{M}^{\text {pro }}$ (gray) complexes. The ligands are bound to the Chain $\mathrm{A}$ of the $\mathrm{M}^{\text {pro }}$, which reflects the differences in the RMSF curves. Three regions show a significant difference between chain A and chain B of the $\mathrm{M}^{\text {pro }}$ in the RMSF. The first region around residue 119 (dashed red rectangle) shows 3-fold higher fluctuations for the $\mathbf{8}-\mathrm{M}^{\text {pro }}$ and $\mathbf{9 -}$ $\mathbf{M}^{\text {pro }}$ than the Apo and the $\mathbf{O 6 K}-\mathbf{M}^{\text {pro }}$. The second region lies around residue 144 (dashed green rectangle) show 1.5-fold higher fluctuations for the 8-Mpro and 9-Mpro compared to the Apo and the O6K-M ${ }^{\text {pro }}$. On the other hand, the third region lies around residue 196 (dashed blue rectangle) and shows 1.5-fold higher fluctuations for the $\mathbf{8}$ - $\mathrm{M}^{\text {pro }}$ than the Apo, O6K-M ${ }^{\text {pro }}$, and 9-M $\mathrm{M}^{\text {pro }}$. 

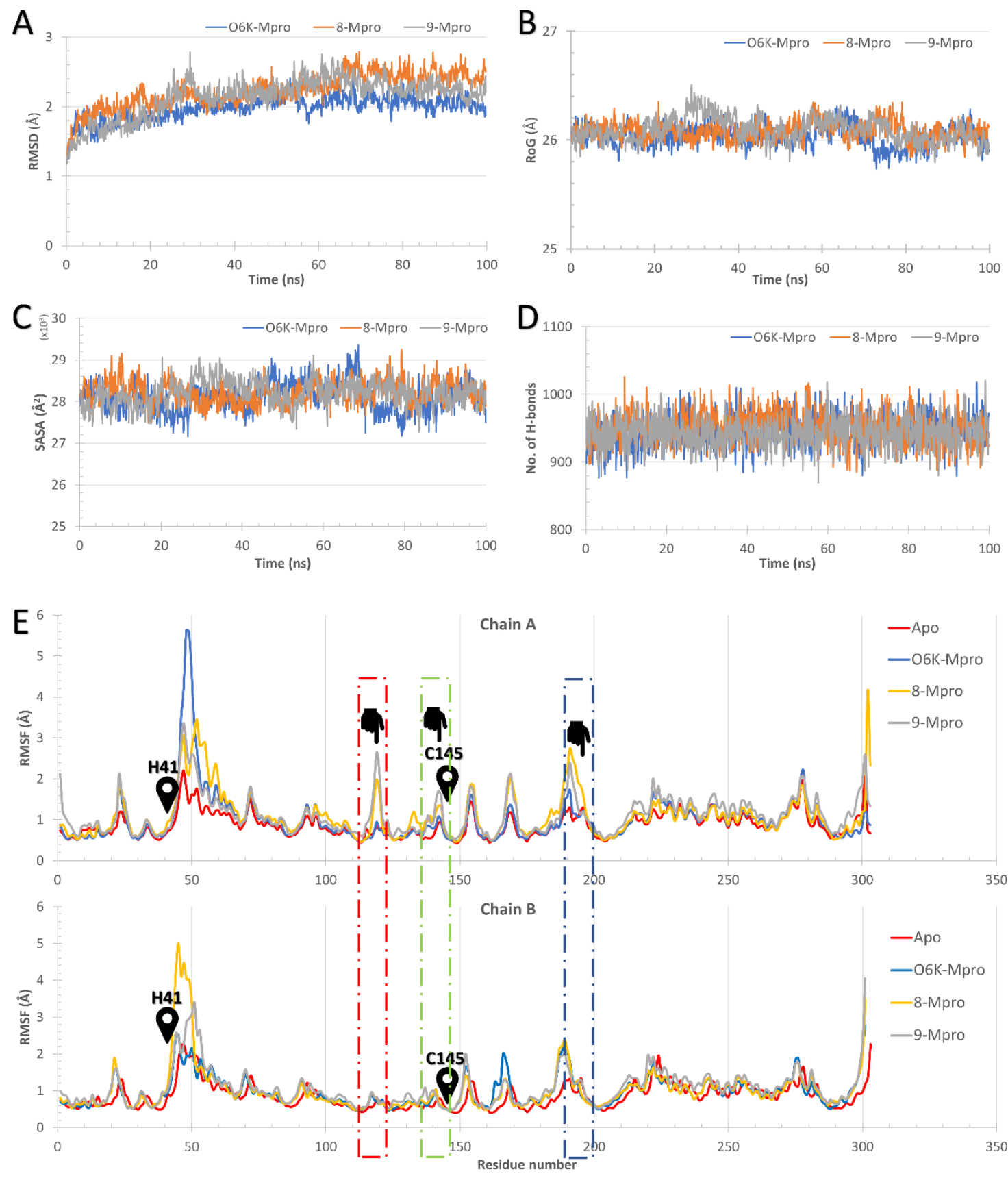

Figure 3: Molecular dynamics simulation data analysis for $\mathbf{O 6 K}-\mathrm{M}^{\mathrm{pro}}, \mathbf{8}-\mathrm{M}^{\mathrm{pro}}$, and $\mathbf{9}-\mathrm{M}^{\mathrm{pro}}$ complexes. (A), (B), (C), and (D) show the RMSD, RoG, SASA, and H-bonds for the O6K-M $\mathbf{M}^{\text {pro }}$ (blue), 8-M $\mathrm{M}^{\text {pro }}$ (orange), and $\mathbf{9}-\mathrm{M}^{\text {pro }}$ (gray) complexes versus the simulation time in ns. (E) shows the per-residue RMSF from the two chains A (upper) and B (lower) of $\mathrm{M}^{\text {pro }}$ in the Apo form (red), O6K-M $\mathrm{M}^{\text {pro }}$ complex (blue), 8- $\mathrm{M}^{\text {pro }}$ complex (orange), and 9-M ${ }^{\text {pro }}$ complex (gray). Active dyads and high fluctuating regions are marked on the curves as illustrated in the text.

To further elucidate each residue's binding energy ( $\mathrm{kcal} / \mathrm{mol})$ contribution, we calculated

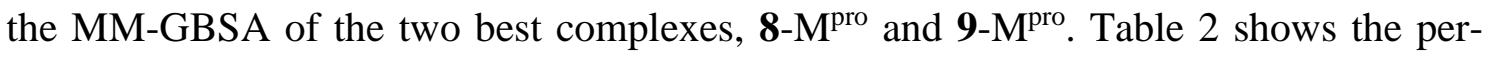
residue decomposition of the binding energy contribution and the different energy term contributions for the total binding energy ( $\left.\Delta \mathrm{G}_{\mathrm{TOTAL}}\right) ; \Delta \mathrm{EVDW}_{\mathrm{VD}}, \Delta \mathrm{E}_{\mathrm{ELE}}, \Delta \mathrm{G}_{\mathrm{GB}}, \Delta \mathrm{G}_{\mathrm{SA}}, \Delta \mathrm{G}_{\mathrm{GAS}}$, 
and $\Delta$ GSOLv. The highest contribution for the residues of the Mpro for the two ligands $\mathbf{8}$ and 9 are listed in bold E166 $(-13.39 \mathrm{kcal} / \mathrm{mol})$ and P168 $(-2.01 \mathrm{kcal} / \mathrm{mol})$ in 8-M $\mathbf{M}^{\text {pro }}$ complex and D248 $(-2.50 \mathrm{kcal} / \mathrm{mol})$ in the 9-M $\mathrm{M}^{\text {pro }}$ complex. Additionally, the ligands (LIG) have a high binding energy contribution in both complexes (-7.48 and -2.48

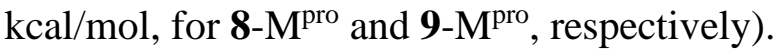

Meanwhile, the residues M165, H172, L167, and F304 moderately contributed to the binding of batzelladine $\mathrm{H}(\mathbf{8})$ to $\mathrm{M}^{\text {pro }}$ with binding energy values of $-0.87,-0.75,-0.67$, and $-0.47 \mathrm{kcal} / \mathrm{mol}$, respectively. While the residues P252, I249, F294, and V297 contributed to the binding of batzelladine $\mathrm{I}(\mathbf{9})$ to $\mathrm{M}^{\text {pro }}$ with binding energy values of $1.28,-1.05,-0.73$, and $-0.44 \mathrm{kcal} / \mathrm{mol}$, respectively. Conversely, S302 (red-bold colored residue) has a negative contribution (positive binding energy) for the binding of compound 8 to the $\mathrm{M}^{\text {pro }}(+1.85 \mathrm{kcal} / \mathrm{mol})$. Based on the total binding energy values of the two complexes, the $8-\mathrm{M}^{\text {pro }}$ has lower total binding energy $(-24.21 \pm 6.32 \mathrm{kcal} / \mathrm{mol})$ compared to the $9-\mathrm{M}^{\text {pro }}(-8.70 \pm 5.29 \mathrm{kcal} / \mathrm{mol})$. Hence, we suggest the effectiveness of compound $\mathbf{8}$ as a promising inhibitor for hunting the $\mathrm{M}^{\text {pro }}$ of SARS-CoV-2.

Table 2: The MM-GBSA calculations for the best two complexes 8- $\mathrm{M}^{\text {pro }}$ and 9- $\mathrm{M}^{\text {pro }}$ calculated after $100 \mathrm{~ns}$ MD simulations utilizing Amber tools 20.

\begin{tabular}{|c|c|c|c|c|}
\hline \multirow[b]{2}{*}{ 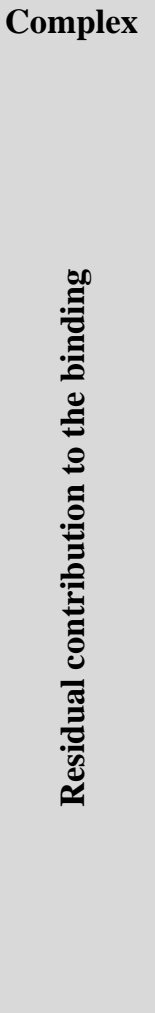 } & \multicolumn{2}{|c|}{ 8-M $\mathbf{M}^{\text {pro }}$ complex } & \multicolumn{2}{|c|}{ 9-M $\mathrm{M}^{\text {pro }}$ complex } \\
\hline & $\begin{array}{c}\text { Residues } \\
\text { E166 } \\
\text { LIG } \\
\text { P168 } \\
\text { M165 } \\
\text { H172 } \\
\text { L167 } \\
\text { F304 } \\
\text { S602 } \\
\text { Q189 } \\
\text { V171 } \\
\text { T169 } \\
\text { A173 } \\
\text { I514 } \\
\text { D187 } \\
\text { R599 } \\
\text { Q600 } \\
\text { R518 } \\
\text { R188 } \\
\text { G170 } \\
\text { S139 } \\
\text { S302 }\end{array}$ & 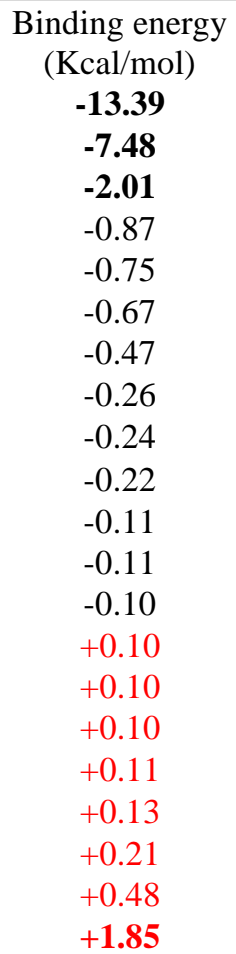 & $\begin{array}{c}\text { Residues } \\
\text { D248 } \\
\text { LIG } \\
\text { P252 } \\
\text { I249 } \\
\text { F294 } \\
\text { V297 } \\
\text { P293 } \\
\text { L253 } \\
\text { V296 } \\
\text { L250 } \\
\text { G251 } \\
\text { K102 } \\
\text { R298 }\end{array}$ & 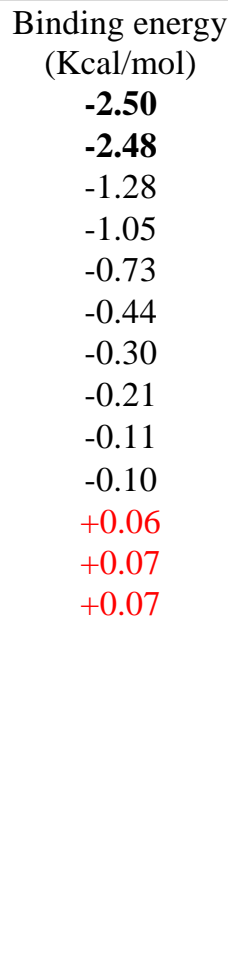 \\
\hline
\end{tabular}




\begin{tabular}{|c|c|c|}
\hline Complex & 8-M $\mathrm{M}^{\text {pro }}$ complex & 9-M ${ }^{\text {pro }}$ complex \\
\hline$\Delta \mathbf{E}_{V D W}$ & -27.85 & -10.37 \\
\hline (kcal/mol) & \pm 4.94 & \pm 5.63 \\
\hline$\Delta \mathrm{E}_{\mathrm{ELE}}$ & -483.16 & -290.35 \\
\hline (kcal/mol) & \pm 53.41 & \pm 74.76 \\
\hline$\Delta \mathbf{G}_{\mathbf{G B}}$ & 491.64 & 294.07 \\
\hline$(\mathrm{kcal} / \mathrm{mol})$ & \pm 51.77 & \pm 75.60 \\
\hline$\Delta \mathbf{G}_{\mathbf{S A}}$ & -4.84 & -2.05 \\
\hline (kcal/mol) & \pm 0.69 & \pm 0.99 \\
\hline$\Delta \mathbf{G}_{\mathrm{GAS}}$ & -511.02 & -300.72 \\
\hline$(\mathrm{kcal} / \mathrm{mol})$ & \pm 55.78 & \pm 78.96 \\
\hline$\Delta \mathbf{G}_{\text {solv }}$ & 486.81 & 292.01 \\
\hline$(\mathrm{kcal} / \mathrm{mol})$ & \pm 51.31 & \pm 74.69 \\
\hline$\Delta \mathbf{G T O T A L}$ & -24.21 & -8.70 \\
\hline$(\mathrm{kcal} / \mathrm{mol})$ & \pm 6.32 & \pm 5.29 \\
\hline
\end{tabular}

\subsection{In Silico Prediction of Pharmacokinetics and Toxicity (ADME/Tox)}

The pharmacokinetic properties for the 15 batzelladine compounds were calculated in silico using the SWISS-ADME and pkCSM online webtools, are summarized in Table 3. Regarding the hydrophobicity of the compounds, they covered a wide spectrum demonstrating a $\log \mathrm{Po} / \mathrm{w}$ between -0.33 to 4.99 . Yet, they all lied below the value of 5 which is the cut-off value for oral bioavailability according to Lipinski's rule of five. On the other hand, all the 15 compounds were poorly to moderately water soluble except for compound 10 which was predicted to be more soluble than the other 14 batzelladines. None of the 15 marine alkaloids exhibited a blood brain barrier permeant ability except derivative 10, thus can generally be considered free from possible CNS side effects. Also, all guanidinic derivatives had zero PAINS alerts i.e., free from pan-assay interferences. Finally, potential cardiotoxicity of this set of marine alkaloids was assessed through evaluation of their potential hurt to the hERGI receptor where none of them was found to be a candidate inhibitor for hERGI.

Table 3: In silico prediction of ADME/Tox profiles of the studied compounds.

$\begin{array}{cccccc}\begin{array}{c}\text { Comp. } \\ \text { No. }\end{array} & \begin{array}{c}\text { Log Po/w } \\ \text { (WLOGP) }\end{array} & \text { Solubility Class } & \begin{array}{c}\text { BBB } \\ \text { Permeant }\end{array} & \begin{array}{c}\text { PAIN } \\ \text { S }\end{array} & \begin{array}{c}\text { hERG I } \\ \text { Inhibitor }\end{array} \\ (\mathbf{1}) & 0.18 & \text { Poorly soluble } & \text { No } & 0 \text { alert } & \text { No } \\ (\mathbf{2}) & -0.33 & \text { Poorly soluble } & \text { No } & 0 \text { alert } & \text { No } \\ (3) & 3.41 & \text { Moderately soluble } & \text { No } & 0 \text { alert } & \text { No } \\ (4) & 1.66 & \text { Moderately soluble } & \text { No } & 0 \text { alert } & \text { No } \\ (5) & 3.19 & \text { Moderately soluble } & \text { No } & 0 \text { alert } & \text { No } \\ (\mathbf{6}) & 3.24 & \text { Poorly soluble } & \text { No } & 0 \text { alert } & \text { No } \\ (7) & 4.12 & \text { Poorly soluble } & \text { No } & 0 \text { alert } & \text { No } \\ (\mathbf{8}) & 4.24 & \text { Poorly soluble } & \text { No } & 0 \text { alert } & \text { No } \\ (\mathbf{9}) & 4.63 & \text { Poorly soluble } & \text { No } & 0 \text { alert } & \text { No } \\ \end{array}$




$\begin{array}{llclll}(\mathbf{1 0}) & 1.07 & \text { Soluble } & \text { Yes } & 0 \text { alert } & \text { No } \\ (\mathbf{1 1}) & 4.02 & \text { Poorly soluble } & \text { No } & 0 \text { alert } & \text { No } \\ (\mathbf{1 2}) & 4.21 & \text { Poorly soluble } & \text { No } & 0 \text { alert } & \text { No } \\ (\mathbf{1 3}) & 4.99 & \text { Poorly soluble } & \text { No } & 0 \text { alert } & \text { No } \\ (\mathbf{1 4}) & 4.18 & \text { Moderately soluble } & \text { No } & 0 \text { alert } & \text { No } \\ (\mathbf{1 5}) & 3.63 & \text { Poorly soluble } & \text { No } & 0 \text { alert } & \text { No }\end{array}$

\subsection{Structure-Activity Relationship (SAR) Studies}

The investigated compounds share a common guanidine-containing structure; two of them possess a tricyclic, a bicyclic, and an acyclic guanidinium cores, which are coupled via an ester linkage, (1) and (2) in Table 4. There are eight derivatives that possesses two tricyclic guanidinium cores, (6-9), (11-13) and (15) in Table 4. In addition, the derivatives (10) and the three derivatives (3-5), (14) in Table 3, possesses only a tricyclic guanidinecontaining core and a tricyclic guanidine-containing core linked to a terminal guanidine by an ester linkage, respectively. Relating the structures (1-15; Scheme 1-2) to the estimated binding scores (Table 4) suggests that the most influential guanidinium core is the two tricyclic guanidine-containing cores coupled via an ester linkage, as can be seen in the predicted binding scores for the eight derivatives (6-9), (11-13), and (15) in (Table $4)$.

From those eight derivatives the most promising inhibitors of the $\mathrm{M}^{\text {pro }}$ enzyme are the derivatives (8) and (9), which have the best predicted free binding energies of -7.12 $\mathrm{kcal} / \mathrm{mol}$ and $-7.00 \mathrm{kcal} / \mathrm{mol}$, respectively. Interestingly, these two derivatives are the only derivatives that possess an aromatic ring embedded in one of the tricyclic guanidine scaffolds. In general, there appears to be a correlation between the unsaturation in the tricyclic guanidine scaffold and the calculated binding score, e.g. the derivative (13) is more unsaturated than its partner (11) and has a predicted $\Delta \mathbf{G}_{\mathbf{B}}$ lower than the predicted one for the derivative (11) (Table 4).

However, some care must be taken in this analysis as the same trend is not obtained for the more unsaturated derivative (14) and its partner (3). The hydroxyl substituent in the position $\mathrm{R}^{4}$ or $\mathrm{R}^{5}$ also appears to improve the calculated binding score, e.g. the derivative (8) with a $N-\mathrm{OH}$ group has a predicted $\Delta \mathbf{G}_{\mathbf{B}}$ lower than that predicted for its partner (6) with a $\mathrm{N}-\mathrm{H}$ group. The same trend was obtained for the two tricyclic guanidine derivatives (7) and (11). The chemical structure of the most promising derivatives (8) and (9) differs in the position of the hydroxyl group in the tricyclic guanidine core, at the $\mathrm{R}^{4}$ or $\mathrm{R}^{5}$ positions. The calculated binding score is improved for the derivative with a hydroxyl 
group at the $\mathrm{R}^{4}$ position (Figure 4). To compare the structural similarity between guanidine-containing derivatives (1-15), and the known inhibitors of the $\mathrm{M}^{\text {pro }}$ enzyme, O6k and N3, the Tanimoto similarity scores (TSS) between them were calculated. Guanidinic derivatives with a higher TSS value were highlighted in bold blue, (Table 4). There is a clear correlation between the highest TSS values and the most promising inhibitors of $\mathrm{M}^{\text {pro }}$ enzyme for the inhibitor O6k. ChemAxon's 3D alignment tool version 5.7.13.0 (ChemAxon Ltd., Budapest, Hungary) was used to align by extended atom types of derivatives with the highest TSS values $(\mathbf{6 , 8 - 9})$ and the inhibitor O6K, (Figure 5). 
Table 4. General structure-activity relationship analysis of the tested structurally related cyclic guanidine-containing marine compounds.

\begin{tabular}{|c|c|c|c|c|c|c|c|c|}
\hline \multirow{2}{*}{ No } & \multicolumn{2}{|c|}{ Guanidinium cores } & \multirow[b]{2}{*}{ Acyclic $^{1}$} & \multirow{2}{*}{$\begin{array}{c}\Delta \mathbf{G}_{\mathbf{B}}^{2} \\
(\mathbf{k c a l} / \mathbf{m o l})\end{array}$} & \multirow{2}{*}{ Chemical Structure } & \multirow{2}{*}{ Antiviral activity } & \multirow{2}{*}{ TSS $^{3}$ to O6K } & \multirow{2}{*}{ TSS $^{3}$ to N3 } \\
\hline & Tricyclic $^{1}$ & Bicyclic $^{1}$ & & & & & & \\
\hline 1 & $\mathrm{R}^{1}=-\mathrm{C}_{9} \mathrm{H}_{19} ; \mathrm{R}^{2}=-\mathrm{CH}_{3} ; \mathrm{R}^{3}=-\mathrm{C}_{8} \mathrm{H}_{16^{-}}$ & $\mathrm{R}^{4}=\stackrel{\mathrm{Y}}{\mathrm{C}_{4} \mathrm{H}_{8-}}$ & Y & -6.54 & & potential & 0.228 & 0.322 \\
\hline 2 & $\mathrm{R}^{1}=-\mathrm{C}_{7} \mathrm{H}_{15} ; \mathrm{R}^{2}=-\mathrm{CH}_{3} ; \mathrm{R}^{3}=-\mathrm{C}_{8} \mathrm{H}_{16^{-}}$ & $\stackrel{\mathrm{Y}}{\mathrm{R}^{4}=-\mathrm{C}_{4} \mathrm{H}_{8}-}$ & Y & -6.36 & & potential & 0.215 & 0.337 \\
\hline 3 & $\stackrel{\mathrm{Y}}{\mathrm{R}^{1}=-\mathrm{C}_{7} \mathrm{H}_{15} ; \mathrm{R}^{2}=-\mathrm{C}_{5} \mathrm{H}_{11} ; \mathrm{R}^{3}=-\mathrm{C}_{4} \mathrm{H}_{8^{-}}}$ & $\mathrm{N}$ & $\mathrm{Y}$ & -6.56 & & potential & 0.223 & 0.385 \\
\hline 4 & $\mathrm{R}^{1}=-\mathrm{C}_{9} \mathrm{H}_{19} ; \mathrm{R}^{2}=\underset{\mathrm{Y}}{\mathrm{Y}}=\mathrm{CH}_{3} ; \mathrm{R}^{3}=-\mathrm{C}_{4} \mathrm{H}_{8^{-}}$ & $\mathrm{N}$ & Y & -6.58 & & potential & 0.245 & 0.358 \\
\hline 5 & $\begin{array}{c}\mathrm{R}^{1}=-\mathrm{C}_{2} \mathrm{H}_{4} \mathrm{CH}=\mathrm{CH}-\mathrm{C}_{3} \mathrm{H}_{7} ; \mathrm{R}^{2}=-\mathrm{C}_{5} \mathrm{H}_{11} \\
\mathrm{R}^{3}=-\mathrm{C}_{4} \mathrm{H}_{8} \\
\mathrm{Y} \text { (two units) }\end{array}$ & $\mathrm{N}$ & Y & -6.56 & & potential & 0.221 & 0.379 \\
\hline 6 & $\begin{array}{c}\mathrm{R}^{1}=-\mathrm{C}_{7} \mathrm{H}_{15} ; \mathrm{R}^{2}=-\mathrm{CH}_{3} ; \\
\mathrm{R}^{3}=-\mathrm{CH}\left(\mathrm{CH}_{3}\right) \mathrm{C}_{7} \mathrm{H}_{4-} ; \mathrm{R}^{4}=-\mathrm{H} ; \mathrm{R}^{5}=-\mathrm{H} \\
\mathrm{Y}(\text { two units })\end{array}$ & $\mathrm{N}$ & $\mathrm{N}$ & -6.84 & & powerful & 0.259 & 0.342 \\
\hline 7 & $\begin{array}{c}\mathrm{R}^{1}=-\mathrm{C}_{9} \mathrm{H}_{19} ; \mathrm{R}^{2}=-\mathrm{CH}_{3} ; \\
\mathrm{R}^{3}=-\mathrm{CH}\left(\mathrm{CH}_{3}\right) \mathrm{C}_{7} \mathrm{H}_{14-} ; \mathrm{R}^{4}=-\mathrm{OH} ; \mathrm{R}^{5}=-\mathrm{H} \\
\mathrm{Y} \text { (two units) }\end{array}$ & $\mathrm{N}$ & $\mathrm{N}$ & -6.84 & & powerful & 0.252 & 0.329 \\
\hline 11 & $\begin{array}{c}\mathrm{R}^{1}=-\mathrm{C}_{9} \mathrm{H}_{19} ; \mathrm{R}^{2}=-\mathrm{CH}_{3} \\
\mathrm{R}^{3}=-\mathrm{CH}\left(\mathrm{CH}_{3}\right) \mathrm{C}_{7} \mathrm{H}_{4-} ; \mathrm{R}^{4}=-\mathrm{H} ; \mathrm{R}^{5}=-\mathrm{H} \\
\mathrm{Y}(\text { two units })\end{array}$ & $\mathrm{N}$ & $\mathrm{N}$ & -6.78 & & & 0.254 & 0.333 \\
\hline 15 & $\begin{array}{c}\mathrm{R}^{1}=-\mathrm{C}_{8} \mathrm{H}_{17} ; \mathrm{R}^{2}=-\mathrm{CH}_{3} \\
\mathrm{R}^{3}=-\mathrm{CH}\left(\mathrm{CH}_{3}\right) \mathrm{C}_{7} \mathrm{H}_{1-4} ; \mathrm{R}^{4}=-\mathrm{H} ; \mathrm{R}^{5}=-\mathrm{H} \\
\mathrm{Y}(\text { two units })\end{array}$ & $\mathrm{N}$ & $\mathrm{N}$ & -6.90 & & yes & 0.256 & 0.337 \\
\hline 8 & $\begin{array}{c}\mathrm{R}^{1}=-\mathrm{C}_{7} \mathrm{H}_{15} ; \mathrm{R}^{2}=-\mathrm{CH}_{3} ; \\
\mathrm{R}^{3}=-\mathrm{C}_{7} \mathrm{H}_{14-} ; \mathrm{R}^{4}=-\mathrm{OH} ; \mathrm{R}^{5}=-\mathrm{H} \\
\mathrm{Y} \text { (two units) }\end{array}$ & $\mathrm{N}$ & $\mathrm{N}$ & -7.12 & & powerful & 0.257 & 0.377 \\
\hline 9 & $\begin{array}{c}\mathrm{R}^{1}=-\mathrm{C}_{7} \mathrm{H}_{15} ; \mathrm{R}^{2}=-\mathrm{CH}_{3} ; \\
\mathrm{R}^{3}=-\mathrm{C}_{7} \mathrm{H}_{14-} ; \mathrm{R}^{4}=-\mathrm{H} ; \mathrm{R}^{5}=-\mathrm{OH}\end{array}$ & $\mathrm{N}$ & $\mathrm{N}$ & -7.00 & & powerful & 0.257 & 0.250 \\
\hline 10 & $\begin{array}{c}\mathrm{Y} \\
\mathrm{R}^{1}=-\mathrm{C}_{5} \mathrm{H}_{11} ; \mathrm{R}^{2}=-\mathrm{CH}_{3}\end{array}$ & $\mathrm{~N}$ & $\mathrm{~N}$ & -5.46 & & & 0.194 & 0.250 \\
\hline
\end{tabular}




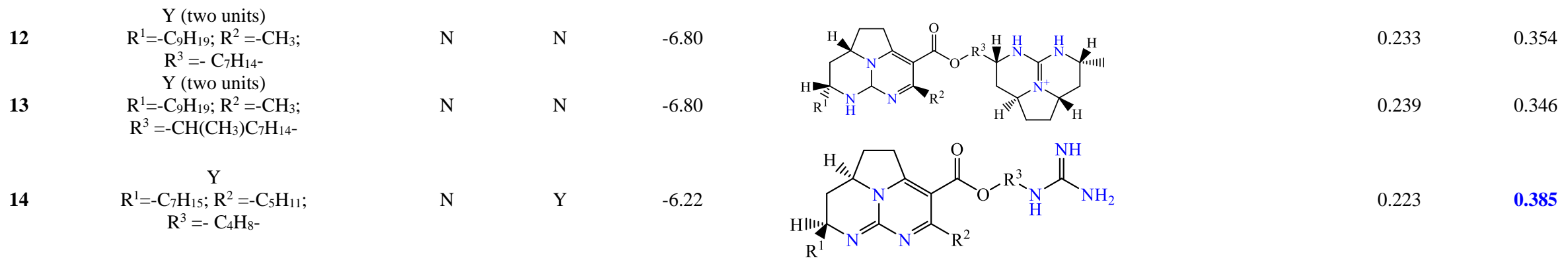

${ }^{1}$ Y-Yes and N, No; ${ }^{2}$ calculated free binding energies against $\mathrm{M}^{\text {pro }}$ enzyme; ${ }^{3}$ Tanimoto similarity score.

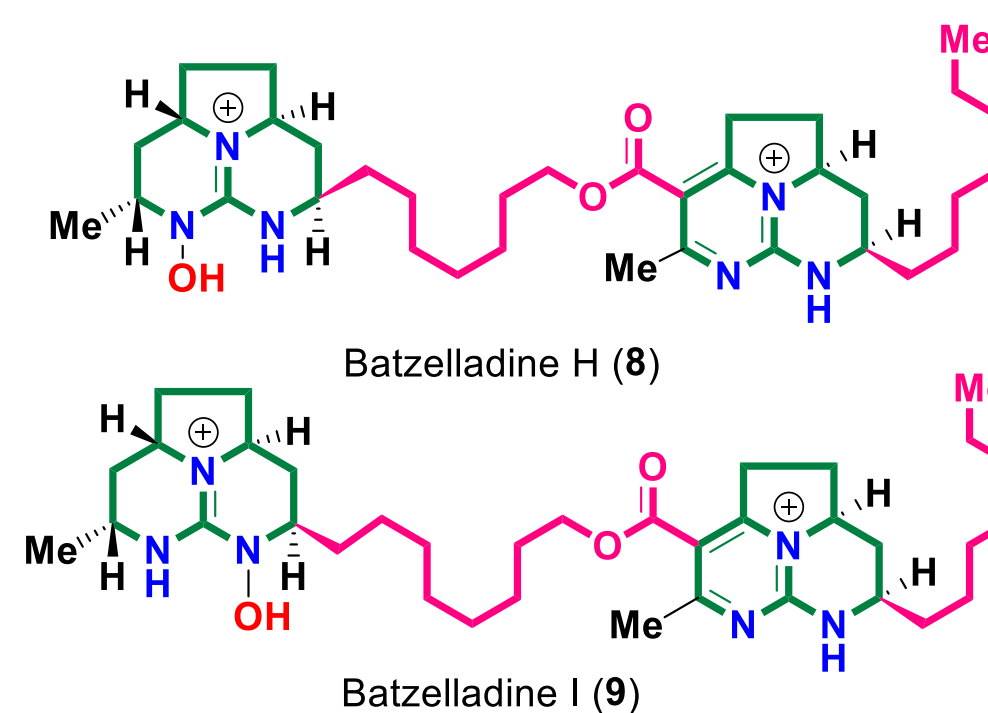

Batzelladine I (9)

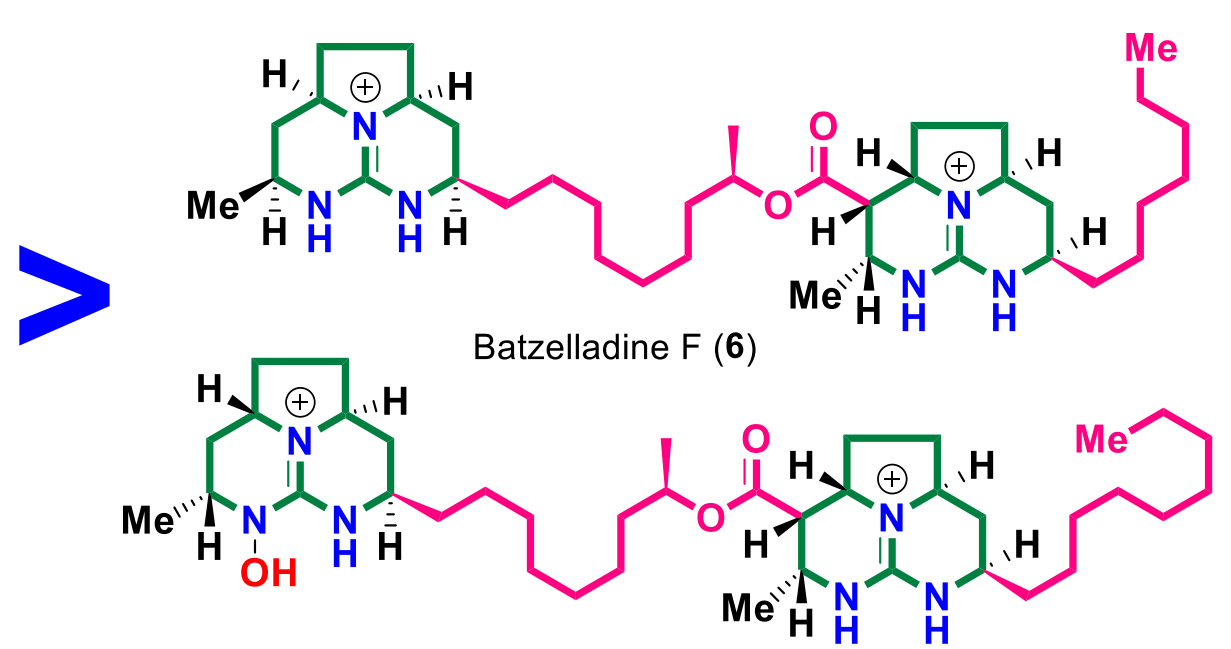

Batzelladine $\mathrm{G}(\mathbf{7})$

Essential for activity

Enhancing activity

Spacer, essential for activity

Figure 4: Chemical structure of the most promising derivatives (6-7) and (8-9) with regarded to $\mathrm{TSS}^{3}$ to $\mathbf{O 6 K}$. 

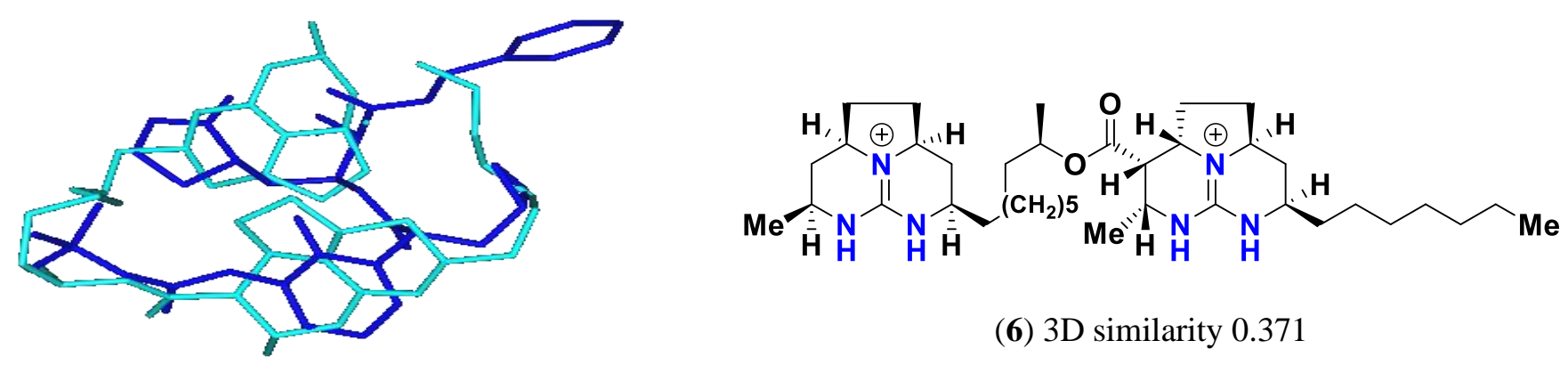

(6) $3 \mathrm{D}$ similarity 0.371
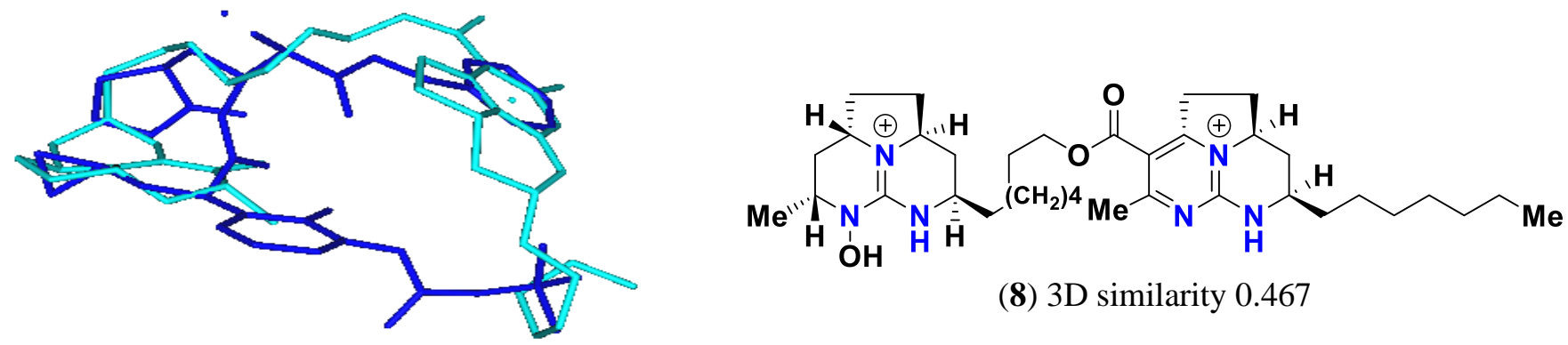

(8) 3D similarity 0.467
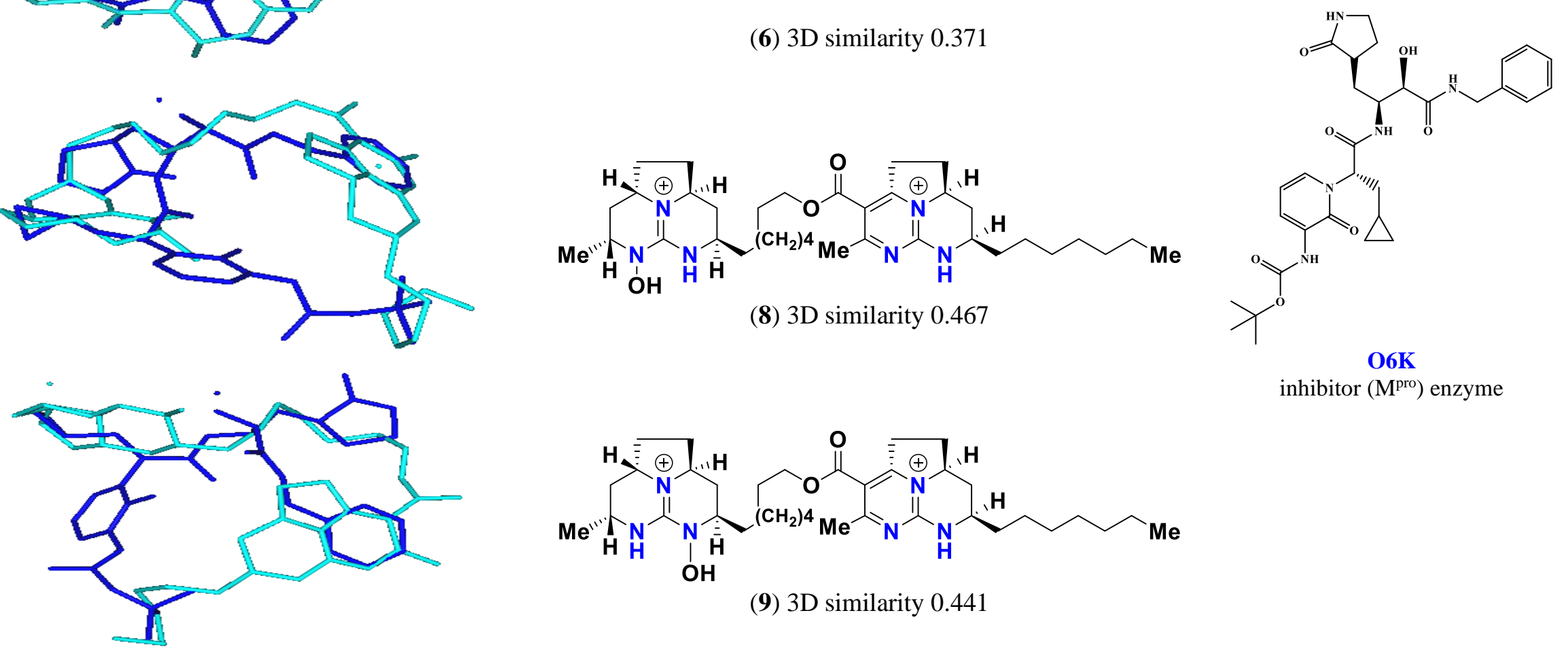

Figure 5: 3D alignment for the most promising derivatives $(6,8-9)$ with $\mathbf{O 6 K}$ inhibitor of $\mathrm{M}^{\text {pro }}$ enzyme. 


\section{Conclusions}

A focused library of fifteen polycyclic marine batzelladine alkaloids were extensively explored for their binding affinities against the dimeric form of the Mpro of SARS-CoV2 using a comprehensive package of computational tools involving MDock, MD and SARs studies. MDock simulations revealed that most of the tested compounds are demonstrating very promising binding scores particularly, batzelladines H-I (8-9) which displayed very close binding scores compared to the co-crystallized inhibitor (O6K, positive control). Indeed, the MD simulations showed an advantageous stability for almost of the investigated marine ligands at the $\left(\mathrm{M}^{\text {pro }}\right)$ binding site. Furthermore, a preliminary SAR study was accomplished to liaise between different structural features and how far they impacted the proposed activity. Those interesting findings figured out that such distinct molecular architectures are merited and could enlighten the development of promising antiviral leads for paving the COVID-19 pandemic. Moreover, considering the feasible total chemical syntheses for a notable number of these compounds [27, 37, 62-64] or structurally related congeners could be encouraging for more in vitro /in vivo preclinical investigations for COVID-19 control. 


\section{CRediT authorship contribution statement}

Conceptualization: Abdo A. Elfiky and Amr El-Demerdash. Validation: Abdo A. Elfiky, Amr El-Demerdash. Formal analysis: Abdo A. Elfiky, Alaa M. Elgohary, Florbela Pereira, Reem K. Arafa and Amr El-Demerdash. Investigation: Abdo A. Elfiky, Alaa M. Elgohary, Florbela Pereira Tarek Mohamed Abdel-Aziz, Mansour Sobeh Reem K. Arafa and Amr El-Demerdash. Resources: Abdo A. Elfiky, Alaa M. Elgohary, Florbela Pereira, Tarek Mohamed Abdel-Aziz, Mansour Sobeh, Reem K. Arafa and Amr El-Demerdash. Data curation: Abdo A. Elfiky, Alaa M. Elgohary, Florbela Pereira, Reem K. Arafa and Amr El-Demerdash. Writing original draft: Abdo A. Elfiky, Alaa M. Elgohary, Florbela Pereira, Tarek Mohamed Abdel-Aziz, Mansour Sobeh, Reem K. Arafa and Amr El-Demerdash. Writing-review \& editing: Abdo A. Elfiky, Alaa M. Elgohary, Florbela Pereira Tarek Mohamed Abdel-Aziz, Mansour Sobeh, Reem K. Arafa and Amr El-Demerdash.

\section{Declaration of competing interest}

The authors declare that they have no known competing financial interests or personal relationships that could have appeared to influence the work reported in this paper.

\section{Funding}

Amr El-Demerdash is immensely grateful to the John Innes Centre, Norwich Research Park, United Kingdom for the postdoctoral fellowship. Florbela Pereira would like to thank Fundacão para a Ciência e a Tecnologia, MCTES, in the scope of the project UIDB/50006/2020 of the Research Unit, Associate Laboratory for Green Chemistry, LAQV".

\section{Acknowledgments}

We thank ChemAxon Ltd. for access to JChem and Marvin. Shaheen supercomputer of King Abdullah University of Science and Technology (KAUST) was utilized for MD simulation calculations (under the project number k1482). 


\section{References}

[1] J.A. Nweze, F.N. Mbaoji, Y.-M. Li, L.-Y. Yang, S.-S. Huang, V.N. Chigor, E.A. Eze, L.-X. Pan, T. Zhang, D.-F. Yang, Potentials of marine natural products against malaria, leishmaniasis, and trypanosomiasis parasites: a review of recent articles, Infectious Diseases of Poverty, 10 (2021) 9.

[2] W. Bergmann, R.J. Feeney, The isolation of a new thymine pentoside from sponges1, Journal of the American Chemical Society, 72 (1950) 2809-2810.

[3] M.F. Stempien, R.F. Nigrelli, G. Pulitzer, Further Observations on the Caribbean Sponge Cryptotethya crypta (de Laubenfels), Nature, 207 (1965) 217-217.

[4] W. Bergmann, R.J. Feeney, Contributions to the Study of Marine Products. XXXII. The nucleosides of sponges. I, The Journal of Organic Chemistry, 16 (1951) 981-987.

[5] R. Montaser, H. Luesch, Marine natural products: a new wave of drugs?, Future Medicinal Chemistry, 3 (2011) 1475-1489.

[6] A. Martins, H. Vieira, H. Gaspar, S. Santos, Marketed Marine Natural Products in the Pharmaceutical and Cosmeceutical Industries: Tips for Success, Marine Drugs, 12 (2014) 1066-1101.

[7] A.M.S. Mayer, K.B. Glaser, C. Cuevas, R.S. Jacobs, W. Kem, R.D. Little, J.M. McIntosh, D.J. Newman, B.C. Potts, D.E. Shuster, The odyssey of marine pharmaceuticals: a current pipeline perspective, Trends in Pharmacological Sciences, 31 (2010) 255-265.

[8] M.A. Ghareeb, M.A. Tammam, A. El-Demerdash, A.G. Atanasov, Insights about clinically approved and Preclinically investigated marine natural products, Current Research in Biotechnology, 2 (2020) 88-102.

[9] A.G. Atanasov, S.B. Zotchev, V.M. Dirsch, I.E. Orhan, M. Banach, J.M. Rollinger, D. Barreca, W. Weckwerth, R. Bauer, E.A. Bayer, M. Majeed, A. Bishayee, V. Bochkov, G.K. Bonn, N. Braidy, F. Bucar, A. Cifuentes, G. D’Onofrio, M. Bodkin, M. Diederich, A.T. Dinkova-Kostova, T. Efferth, K. El Bairi, N. Arkells, T.-P. Fan, B.L. Fiebich, M. Freissmuth, M.I. Georgiev, S. Gibbons, K.M. Godfrey, C.W. Gruber, J. Heer, L.A. Huber, E. Ibanez, A. Kijjoa, A.K. Kiss, A. Lu, F.A. Macias, M.J.S. Miller, A. Mocan, R. Müller, F. Nicoletti, G. Perry, V. Pittalà, L. Rastrelli, M. Ristow, G.L. Russo, A.S. Silva, D. Schuster, H. Sheridan, K. Skalicka-Woźniak, L. Skaltsounis, E. Sobarzo-Sánchez, D.S. Bredt, H. Stuppner, A. Sureda, N.T. Tzvetkov, R.A. Vacca, B.B. Aggarwal, M. Battino, F. Giampieri, M. Wink, J.-L. Wolfender, J. Xiao, A.W.K. Yeung, G. Lizard, M.A. Popp, M. Heinrich, I. Berindan-Neagoe, M. Stadler, M. Daglia, R. Verpoorte, C.T. Supuran, T. 
the International Natural Product Sciences, Natural products in drug discovery: advances and opportunities, Nature Reviews Drug Discovery, 20 (2021) 200-216.

[10] M. Martins, R. Silva, M. M. M. Pinto, E. Sousa, Marine Natural Products, Multitarget Therapy and Repurposed Agents in Alzheimer's Disease, Pharmaceuticals, 13 (2020) 242.

[11] C. Lyu, T. Chen, B. Qiang, N. Liu, H. Wang, L. Zhang, Z. Liu, CMNPD: a comprehensive marine natural products database towards facilitating drug discovery from the ocean, Nucleic Acids Research, 49 (2020) D509-D515.

[12] S.A. Dyshlovoy, F. Honecker, Marine Compounds and Cancer: Updates 2020, Marine Drugs, 18 (2020) 643.

[13] D.E. Williams, R.J. Andersen, Biologically active marine natural products and their molecular targets discovered using a chemical genetics approach, Natural Product Reports, 37 (2020) 617-633.

[14] A.R. Carroll, B.R. Copp, R.A. Davis, R.A. Keyzers, M.R. Prinsep, Marine natural products, Natural Product Reports, 37 (2020) 175-223.

[15] C. Vizetto-Duarte, P. Castelo-Branco, L. Custódio, Marine natural products as a promising source of therapeutic compounds to target cancer stem cells, Current medicinal chemistry, (2021).

[16] S. Fakhri, A. Yarmohammadi, M. Yarmohammadi, M.H. Farzaei, J. Echeverria, Marine Natural Products: Promising Candidates in the Modulation of Gut-Brain Axis towards Neuroprotection, Marine Drugs, 19 (2021) 165.

[17] A.R. Carroll, B.R. Copp, R.A. Davis, R.A. Keyzers, M.R. Prinsep, Marine natural products, Natural product reports, 38 (2021) 362-413.

[18] J.A. Nweze, F.N. Mbaoji, Y.-M. Li, L.-Y. Yang, S.-S. Huang, V.N. Chigor, E.A. Eze, L.-X. Pan, T. Zhang, D.-F. Yang, Potentials of marine natural products against malaria, leishmaniasis, and trypanosomiasis parasites: a review of recent articles, Infectious Diseases of Poverty, 10 (2021) 1-19.

[19] E. Manzo, Synthesis of Marine Natural Products and Molecules Inspired by Marine Substances, Marine Drugs, 19 (2021) 208.

[20] W.-Y. Lu, H.-J. Li, Q.-Y. Li, Y.-C. Wu, Application of marine natural products in drug research, Bioorganic \& Medicinal Chemistry, 35 (2021) 116058.

[21] J.P. Wong, B. Damania, SARS-CoV-2 dependence on host pathways, Science, 371 (2021) 884-885. 
[22] M.A. Martinez, Plitidepsin: a Repurposed Drug for the Treatment of COVID-19, Antimicrobial Agents and Chemotherapy, 65 (2021) e00200-00221.

[23] J.F. Varona, P. Landete, J.A. Lopez-Martin, V. Estrada, R. Paredes, P. GuisadoVasco, L. Fernandez de Orueta, M. Torralba, J. Fortun, R. Vates, J. Barberan, B. Clotet, J. Ancochea, D. Carnevali, N. Cabello, L. Porras, P. Gijon, A. Monereo, D. Abad, S. Zuñiga, I. Sola, J. Rodon, J. Vergara-Alert, N. Izquierdo-Useros, S. Fudio, M.J. Pontes, B. de Rivas, P. Giron de Velasco, A. Nieto, J. Gomez, P. Aviles, R. Lubomirov, A. Belgrano, B. Sopesen, K.M. White, R. Rosales, S. Yildiz, A.-K. Reuschl, L.G. Thorne, C. Jolly, G.J. Towers, L. Zuliani-Alvarez, M. Bouhaddou, K. Obernier, B.L. McGovern, M.L. Rodriguez, L. Enjuanes, J.M. Fernandez-Sousa, N.J. Krogan, J.M. Jimeno, A. Garcia-Sastre, Preclinical and randomized phase I studies of plitidepsin in adults hospitalized with COVID-19, Life Science Alliance, 5 (2022) e202101200.

[24] K.M. White, R. Rosales, S. Yildiz, T. Kehrer, L. Miorin, E. Moreno, S. Jangra, M.B. Uccellini, R. Rathnasinghe, L. Coughlan, C. Martinez-Romero, J. Batra, A. Rojc, M. Bouhaddou, J.M. Fabius, K. Obernier, M. Dejosez, M.J. Guillén, A. Losada, P. Avilés, M. Schotsaert, T. Zwaka, M. Vignuzzi, K.M. Shokat, N.J. Krogan, A. García-Sastre, Plitidepsin has potent preclinical efficacy against SARS-CoV-2 by targeting the host protein eEF1A, Science, 371 (2021) 926-931.

[25] A. El-Demerdash, A.G. Atanasov, A. Bishayee, M. Abdel-Mogib, J.N.A. Hooper, A. Al-Mourabit, Batzella, Crambe and Monanchora: Highly Prolific Marine Sponge Genera Yielding Compounds with Potential Applications for Cancer and Other Therapeutic Areas, Nutrients, 10 (2018) 33.

[26] A.E. Demerdash, Isolation of Bioactive Marine Natural Products and Bioinspired Synthesis of Fused Guanidinic Tricyclic Analogues, Université Paris-Saclay (ComUE), 2016.

[27] A. El-Demerdash, L. Ermolenko, E. Gros, P. Retailleau, B.N. Thanh, G.-B. Anne, A. Al-Mourabit, Short-Cut Bio-Inspired Synthesis of Tricyclic Guanidinic Motifs of Crambescidins and Batzelladines Marine Alkaloids, European Journal of Organic Chemistry, n/a.

[28] B.B. Snider, W.C. Faith, The total synthesis of $( \pm)$ - ptilocaulin, Tetrahedron Letters, 24 (1983) 861-864.

[29] S.B.L. Silva, F. Oberhänsli, M.-A. Tribalat, G. Genta-Jouve, J.-L. Teyssié, M.-Y. Dechraoui-Bottein, J.-F. Gallard, L. Evanno, E. Poupon, O.P. Thomas, Insights into the 
Biosynthesis of Cyclic Guanidine Alkaloids from Crambeidae Marine Sponges, Angewandte Chemie International Edition, 58 (2019) 520-525.

[30] S. Mai, V. Nagulapalli, A. Patil, A. Truneh, J. Westley, Marine compounds as HIV inhibitors, US Patent Application No. WO9301193 (A1), 21 (1993).

[31] A.D. Patil, N.V. Kumar, W.C. Kokke, M.F. Bean, A.J. Freyer, C.D. Brosse, S. Mai, A. Truneh, B. Carte, Novel alkaloids from the sponge Batzella sp.: inhibitors of HIV gp120-human CD4 binding, The Journal of Organic Chemistry, 60 (1995) 1182-1188.

[32] A.D. Patil, A.J. Freyer, P.B. Taylor, B. Carté, G. Zuber, R.K. Johnson, D.J. Faulkner, Batzelladines F- I, Novel Alkaloids from the Sponge Batzella sp.: inducers of p56lckCD4 Dissociation, The Journal of Organic Chemistry, 62 (1997) 1814-1819.

[33] H.-M. Hua, J. Peng, D.C. Dunbar, R.F. Schinazi, A.G. de Castro Andrews, C. Cuevas, L.F. Garcia-Fernandez, M. Kelly, M.T. Hamann, Batzelladine alkaloids from the caribbean sponge Monanchora unguifera and the significant activities against HIV-1 and AIDS opportunistic infectious pathogens, Tetrahedron, 63 (2007) 11179-11188.

[34] L. Kohn, P. Porto, B. Bianchi, M. Santos, R. Berlinck, C. Arns, NOR-Batzelladine L from the sponge Monanchora sp. displays antiviral acyivity against Herpes Simplex virus type 1, Planta Medica, 78 (2012) CL27.

[35] A. Olszewski, K. Sato, Z.D. Aron, F. Cohen, A. Harris, B.R. McDougall, W.E. Robinson, L.E. Overman, G.A. Weiss, Guanidine alkaloid analogs as inhibitors of HIV1 Nef interactions with p53, actin, and p56lck, Proceedings of the National Academy of Sciences, 101 (2004) 14079-14084.

[36] N. Ahmed, K.G. Brahmbhatt, S.I. Khan, M. Jacob, B.L. Tekwani, S. Sabde, D. Mitra, I.P. Singh, I.A. Khan, K.K. Bhutani, Synthesis and biological evaluation of tricyclic guanidine analogues of batzelladine $\mathrm{K}$ for antimalarial, antileishmanial, antibacterial, antifungal and anti-HIV activities, Chemical biology \& drug design, (2012) no-no.

[37] E.L. Bennett, G.P. Black, P. Browne, A. Hizi, M. Jaffar, J.P. Leyland, C. Martin, I. Oz-Gleenberg, P.J. Murphy, T.D. Roberts, Synthesis and biological activity of analogues of batzelladine F, Tetrahedron, 69 (2013) 3061-3066.

[38] A. El-Demerdash, A.G. Atanasov, O.K. Horbanczuk, M.A. Tammam, M. AbdelMogib, J.N.A. Hooper, N. Sekeroglu, A. Al-Mourabit, A. Kijjoa, Chemical Diversity and Biological Activities of Marine Sponges of the Genus Suberea: A Systematic Review, Marine Drugs, 17 (2019) 115. 
[39] A. El-Demerdash, C. Moriou, J. Toullec, M. Besson, S. Soulet, N. Schmitt, S. Petek, D. Lecchini, C. Debitus, A. Al-Mourabit, Bioactive Bromotyrosine-Derived Alkaloids from the Polynesian Sponge Suberea ianthelliformis, Marine Drugs, 16 (2018) 146.

[40] A. El-Demerdash, D. Kumla, A. Kijjoa, Chemical Diversity and Biological Activities of Meroterpenoids from Marine Derived-Fungi: A Comprehensive Update, Marine Drugs, 18 (2020) 317.

[41] A. El-Demerdash, A.M. Metwaly, A. Hassan, T.M. Abd El-Aziz, E.B. Elkaeed, I.H. Eissa, R.K. Arafa, J.D. Stockand, Comprehensive Virtual Screening of the Antiviral Potentialities of Marine Polycyclic Guanidine Alkaloids against SARS-CoV-2 (COVID19), Biomolecules, 11 (2021) 460.

[42] A. El-Demerdash, A.A. Al-Karmalawy, T.M. Abdel-Aziz, S.S. Elhady, K.M. Darwish, A.H. Hassan, Investigating the structure-activity relationship of marine natural polyketides as promising SARS-CoV-2 main protease inhibitors, RSC Advances, 11 (2021) 31339-31363.

[43] A. El-Demerdash, A. Hassan, T.M. Abd El-Aziz, J.D. Stockand, R.K. Arafa, Marine Brominated Tyrosine Alkaloids as Promising Inhibitors of SARS-CoV-2, Molecules, 26 (2021) 6171.

[44] M.D. Hanwell, D.E. Curtis, D.C. Lonie, T. Vandermeersch, E. Zurek, G.R. Hutchison, Avogadro: an advanced semantic chemical editor, visualization, and analysis platform, J Cheminform, 4 (2012) 17.

[45] A.K. Rappe, C.J. Casewit, K.S. Colwell, W.A. Goddard, W.M. Skiff, UFF, a full periodic table force field for molecular mechanics and molecular dynamics simulations, Journal of the American Chemical Society, 114 (2002) 10024-10035.

[46] Z. Bikadi, E. Hazai, Application of the PM6 semi-empirical method to modeling proteins enhances docking accuracy of AutoDock, J Cheminform, 1 (2009) 15.

[47] L. Zhang, D. Lin, X. Sun, U. Curth, C. Drosten, L. Sauerhering, S. Becker, K. Rox, R. Hilgenfeld, Crystal structure of SARS-CoV-2 main protease provides a basis for design of improved \&\#x3b1;-ketoamide inhibitors, Science, 368 (2020) 409-412.

[48] Z. Jin, X. Du, Y. Xu, Y. Deng, M. Liu, Y. Zhao, B. Zhang, X. Li, L. Zhang, C. Peng, Y. Duan, J. Yu, L. Wang, K. Yang, F. Liu, R. Jiang, X. Yang, T. You, X. Liu, X. Yang, F. Bai, H. Liu, X. Liu, L.W. Guddat, W. Xu, G. Xiao, C. Qin, Z. Shi, H. Jiang, Z. Rao, H. Yang, Structure of Mpro from SARS-CoV-2 and discovery of its inhibitors, Nature, 582 (2020) 289-293. 
[49] G.M. Morris, R. Huey, W. Lindstrom, M.F. Sanner, R.K. Belew, D.S. Goodsell, A.J. Olson, AutoDock4 and AutoDockTools4: Automated docking with selective receptor flexibility, J Comput Chem, 30 (2009) 2785-2791.

[50] O. Trott, A.J. Olson, AutoDock Vina: improving the speed and accuracy of docking with a new scoring function, efficient optimization, and multithreading, J Comput Chem, 31 (2010) 455-461.

[51] J.C. Phillips, R. Braun, W. Wang, J. Gumbart, E. Tajkhorshid, E. Villa, C. Chipot, R.D. Skeel, L. Kale, K. Schulten, Scalable molecular dynamics with NAMD, J Comput Chem, 26 (2005) 1781-1802.

[52] J. Huang, A.D. MacKerell, Jr., CHARMM36 all-atom additive protein force field: validation based on comparison to NMR data, J Comput Chem, 34 (2013) 2135-2145.

[53] M.F. Harrach, B. Drossel, Structure and dynamics of TIP3P, TIP4P, and TIP5P water near smooth and atomistic walls of different hydroaffinity, The Journal of Chemical Physics, 140 (2014) 174501.

[54] P. Mark, L. Nilsson, Structure and dynamics of the TIP3P, SPC, and SPC/E water models at 298 K, The Journal of Physical Chemistry A, 105 (2001) 9954-9960.

[55] W. Humphrey, A. Dalke, K. Schulten, VMD: visual molecular dynamics, Journal of molecular graphics, 14 (1996) 33-38, 27-38.

[56] E.F. Pettersen, T.D. Goddard, C.C. Huang, G.S. Couch, D.M. Greenblatt, E.C. Meng, T.E. Ferrin, UCSF Chimera - a visualization system for exploratory research and analysis, Journal of computational chemistry, 25 (2004) 1605-1612.

[57] S. Genheden, U. Ryde, The MM/PBSA and MM/GBSA methods to estimate ligandbinding affinities, Expert Opin Drug Discov, 10 (2015) 449-461.

[58] A. Daina, O. Michielin, V. Zoete, SwissADME: a free web tool to evaluate pharmacokinetics, drug-likeness and medicinal chemistry friendliness of small molecules, Scientific Reports, 7 (2017) 42717.

[59] J.B. Baell, G.A. Holloway, New Substructure Filters for Removal of Pan Assay Interference Compounds (PAINS) from Screening Libraries and for Their Exclusion in Bioassays, Journal of Medicinal Chemistry, 53 (2010) 2719-2740.

[60] D.E.V. Pires, T.L. Blundell, D.B. Ascher, pkCSM: Predicting Small-Molecule Pharmacokinetic and Toxicity Properties Using Graph-Based Signatures, Journal of Medicinal Chemistry, 58 (2015) 4066-4072.

[61] E. Sfecci, T. Lacour, P. Amade, M. Mehiri, Polycyclic guanidine alkaloids from Poecilosclerida marine sponges, Marine drugs, 14 (2016) 77. 
[62] Y.-C. Lin, A. Ribaucourt, Y. Moazami, J.G. Pierce, Concise Synthesis and Antimicrobial Evaluation of the Guanidinium Alkaloid Batzelladine D: Development of a Stereodivergent Strategy, Journal of the American Chemical Society, 142 (2020) 98509857.

[63] Y. Guo, Z. Gao, G. Huang, H. Zhong, X. Meng, H. Tang, C. Zou, Synthesis of the chiral intermediate of batzelladines A and B, Phosphorus, Sulfur, and Silicon and the Related Elements, 192 (2017) 113-117.

[64] N.R. Babij, J.P. Wolfe, Asymmetric Total Synthesis of (+)-Merobatzelladine B, Angewandte Chemie International Edition, 51 (2012) 4128-4130. 